\title{
Effects of urbanization on the land sea breeze circulation over the Pearl River Delta region in winter
}

\author{
Xi Lu, ${ }^{\text {a,b }}$ Kim-Chiu Chow, ${ }^{\text {b,c* } * \text { Teng Yao, }}{ }^{\text {b Alexis K. H. Lau }}{ }^{\text {b,d }}$ and Jimmy C. H. Fung ${ }^{\mathrm{b}, \mathrm{c}}$ \\ ${ }^{a}$ Department of Atmospheric Science, Nanjing University of Information Science \& Technology, No. 219 Ningliu Road, Pukou District, Nanjing, \\ Jiangsu Province, 210044, People's Republic of China \\ b Atmospheric Research Center, The Hong Kong University of Science \& Technology Fok Ying Tung Graduate School, Nansha, Guangzhou, \\ China \\ c Department of Mathematics, The Hong Kong University of Science \& Technology, Clear Water Bay, Hong Kong, China \\ d Environmental Central Facility, Institute for the Environment, The Hong Kong University of Science \& Technology, Clear Water Bay, Hong \\ Kong, China
}

\begin{abstract}
In this study, the fifth-generation Pennsylvania State University-National Center for Atmospheric Research Model (MM5) was used to investigate the effects of urbanization on land-sea breezes (LSBs) in the Pearl River Delta (PRD) region, which is a rapidly developing area located in southern China. LSBs in the 2003/2004 winter were simulated utilizing an approach in which the NCEP Final Analysis data averaged in the 2003/2004 winter is used as initial and lateral boundary conditions for the model. The simulated surface winds are shown to be capable of reproducing the basic features and diurnal variation of the LSBs. Sensitivity experiments with changes in land uses were performed with this model. Results of these experiments show that urbanization in the PRD region can have significant effects on the patterns of the LSBs and circulation in the region. In particular, it has been shown that the urbanization of Shenzhen (a major city located in the eastern coast of the PRD and neighbouring to the north of Hong Kong) may significantly enhance the sea breeze to the west of Hong Kong in the early afternoon. This may enhance the low-level convergence in Hong Kong and may worsen the air pollution problem there. On the other hand, the effects of urbanization in the western coast of the PRD region are relatively local and LSBs on the eastern PRD are generally not affected. Copyright (C) 2009 Royal Meteorological Society
\end{abstract}

KEY WORDS land sea breeze; urbanization; Pearl River delta

Received 26 August 2008; Revised 27 January 2009; Accepted 14 April 2009

\section{Introduction}

The Pearl River Delta (PRD) region is located in southern China with a population over 50 million and including some major cities of China including Guangzhou, Shenzhen, Hong Kong, Macau, Dongguan and Zhuhai (Figure 1(b)). As a result of policy change and economic growth, this region has experienced enormous changes since the 1980s and has become one of the world's largest industrial zones. However, the rapid urbanization and industrial development in the region also led to severe air pollution problems such as high concentrations of ozone and particulate matter (Fung et al., 2005; Wang et al., 2007). Previous studies have suggested that land-sea breezes (LSBs) and heat island circulation are closely related to regional air pollution problems (Vukovich et al., 1971; Bornstein et al., 1975; Sawai et al., 1978). Because most of the urban areas in the PRD region are located near the coastal region, it is likely that urbanization in this region can have significant

\footnotetext{
* Correspondence to: Kim-Chiu Chow, Department of Mathematics, The Hong Kong University of Science \& Technology, Clear Water Bay, Hong Kong, China. E-mail: kchow@ust.hk
}

impacts on the LSBs and regional circulations. Particularly, some previous studies have suggested that the LSB circulation in the PRD region may significantly influence the airflow pattern and air quality over Hong Kong (Kok et al., 1997; Fung et al., 2005; Huang et al., 2005; Lo et al., 2006).

Some numerical studies have been conducted to study the influence of urban modification on LSBs over the PRD. For example, Ding et al. (2004) simulated LSBs in the PRD region and investigated the transport of pollutants during a prolonged ozone episode. Tong et al. (2005) also simulated the urban boundary layer over the complex terrain of Hong Kong, and their simulations suggested that urban heat island and the occurrence of a LSB circulation can have significant impacts on air pollution transport and dispersion. Lin et al. (2007) and Lo et al. (2007) used different land use datasets to investigate the changes in meteorological conditions associated with a typical air pollution case.

Although some features of LSBs associated with the urbanization in the PRD region have been revealed by these studies, the general effects of urbanization on the LSB circulation, e.g. on a seasonal scale, are not easily 
(a)

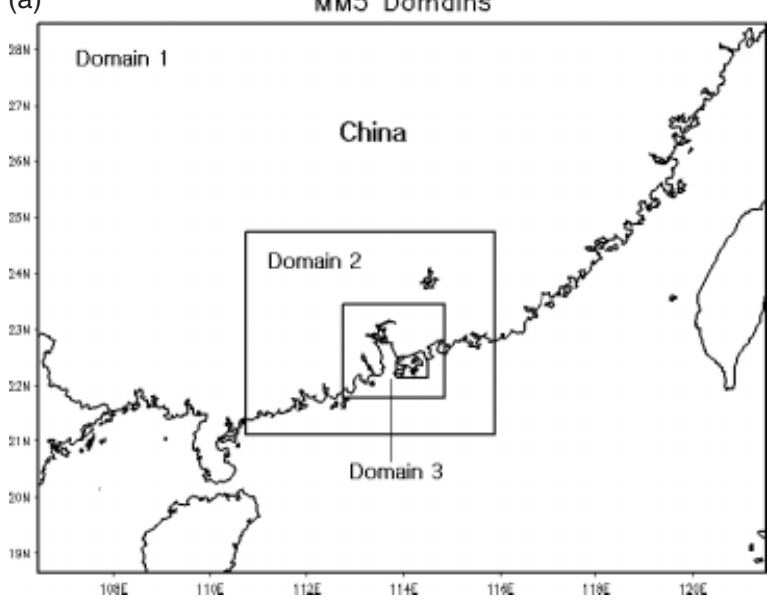

(b)

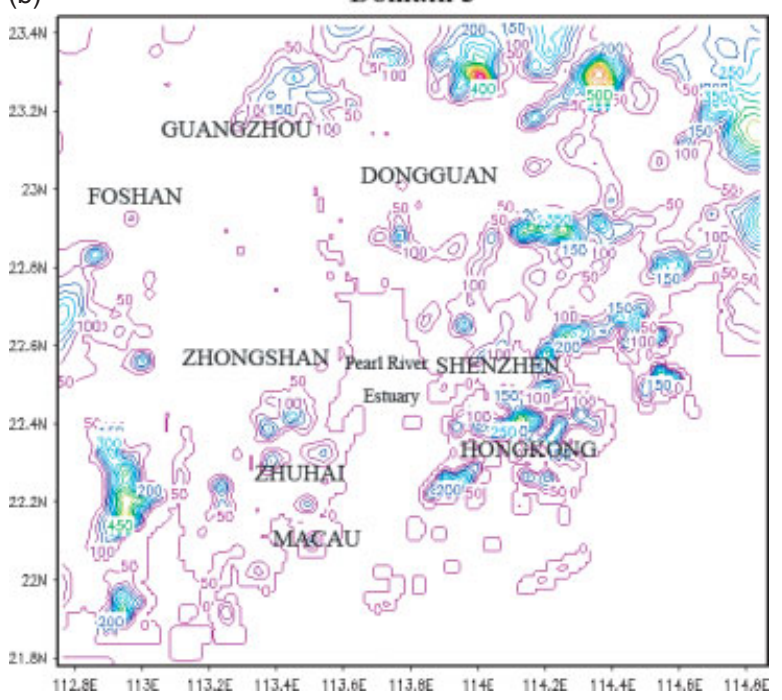

Figure 1. (a) Domains for MM5 Simulations (b) Enlarged view of domain 3 (D3) showing the terrain (m, contours) and locations of some major cities in the Pearl River Delta region. This figure is available in colour online at www.interscience.wiley.com/ijoc

concluded from these previous works since these are case studies for a period of a few days or under particular situations such as typhoons or fronts. To the knowledge of the authors, the seasonal mean LSBs and wind field in the PRD region have not been addressed in the existing literature. It may be due to the relatively few and sparse distribution of the weather stations in the region and the expensive computing cost in obtaining the seasonal mean model simulations in such a fine spatial scale.

In this study, we used the mesoscale Pennsylvania State University-National Center for Atmospheric Research Model (Penn State/NCAR) MM5 to investigate how different scenarios of urbanization in the PRD region might have affected the seasonal mean structure and diurnal variations of the local circulation and LSBs in the region during the winter between 2003 and 2004. Simulating the LSB circulation utilizing a highresolution mesoscale model for a whole winter is very computationally expensive, particularly with the addition of sensitivity experiments. Therefore, a new approach in simulating the seasonal LSB circulation is introduced in this study. In this approach, the NCEP Final Analysis data averaged in the 2003/2004 winter is used as initial and lateral boundary conditions. The year 2004 is chosen in this study because the LSB circulation simulated by this new approach can be validated with the existing data of normal MM5 runs for the whole winter between 2003 and 2004 (which will be further discussed in the next section). Three sensitivity experiments with changes in land use were then carried out with the models using the new approach. This study will focus on winter because according to observations, the frequency of LSBs in winter is higher than in other seasons (Zhang et al., 1999) and high air pollution episodes often occur in autumn and winter. The season of autumn was not considered in this study because tropical cyclones often occur in early autumn (September) in this region. Therefore, when studying the seasonal mean features in the PRD region using the approach presented in this study, winter is more appropriate since in winter the weather in southern China is generally calm and fair with prevailing northeasterly wind associated with the winter monsoon.

The model set-up, experimental designs and data used in this study will be discussed in Section 2. Description and results of the three sensitivity experiments will be discussed in Section 3. The main conclusions of this study will be summarized in Section 4.

\section{The numerical model}

\subsection{Model set-up}

The numerical model used in this study is the fifthgeneration Penn State/NCAR MM5 version 3.7 (Dudhia et al., 1993). Three nested domains with horizontal grid spacing of $13.5 \mathrm{~km}$ (D1), $4.5 \mathrm{~km} \mathrm{(D2)} \mathrm{and} 1.5 \mathrm{~km}$ (D3) are used (Figure 1(a)). The smallest domain D3 is designed to resolve the regional-scale circulation features over the PRD. There are 35 vertical sigma layers in all domains, with the lowest 12 levels allocated below the altitude of $1 \mathrm{~km}$ in order to have a finer resolution of the planetary boundary layer (PBL).

As indicated in some previous studies (e.g. Chen and Dudhia, 2001; Lo et al., 2007), the original land use data used by MM5 from the U.S. Geological Survey (USGS) (Figure 2(b)) is not up to date (last updated 1993) for the PRD region, as urban areas have significantly increased during the past decades. In this study, the recently updated land use data, which was originally compiled by the Planning Department of the Hong Kong SAR Government (HKPD) in 2003 (HKPD, 2003), is used as in Lo et al. (2007) (Figure 2(a)). The highresolution $(30 \mathrm{~m})$ HKPD land use data was reformatted to supersede the original 30 arc second in the MM5 data over the PRD region.

The NCEP Final Analysis (FNL) data of $1^{\circ}$ latitude/longitude resolution averaged for the 3 months of the winter from December 2003 to February 2004 is used as the initial and lateral boundary conditions for 
(a)

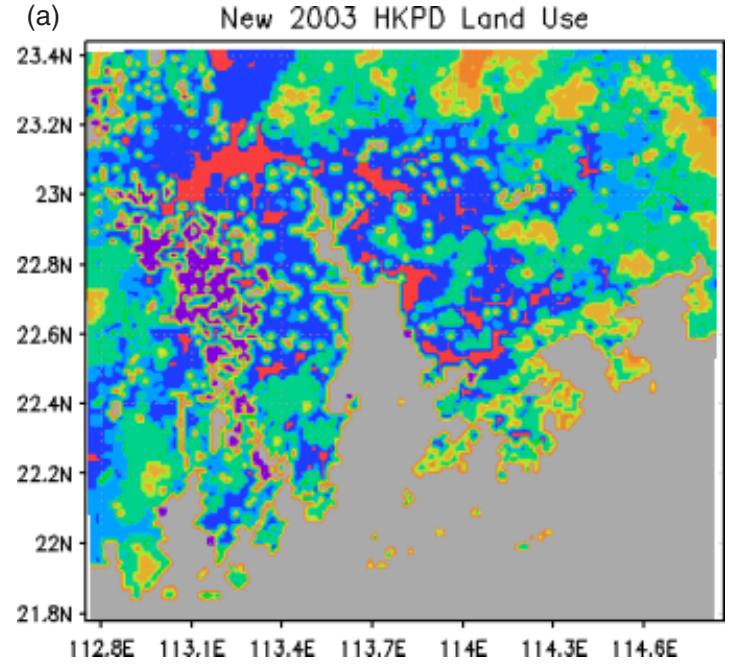

(c) New Land Use (without Shenzhen)

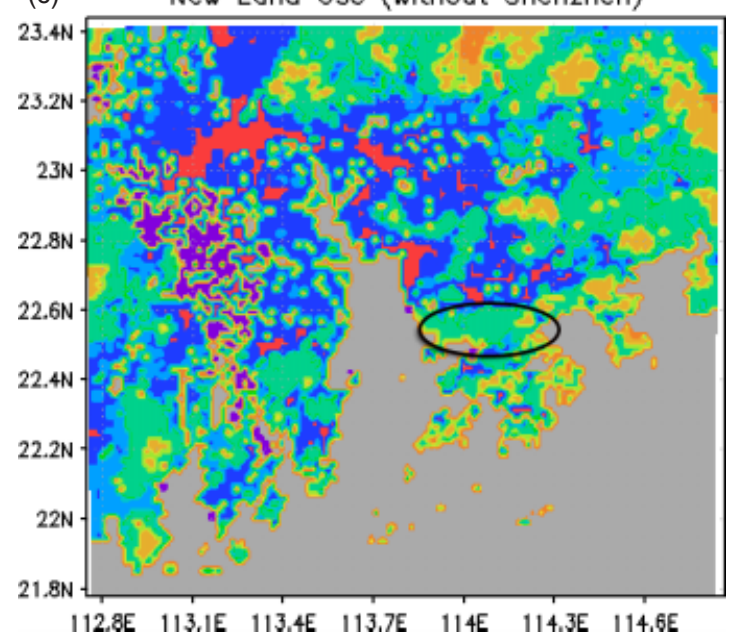

(b)

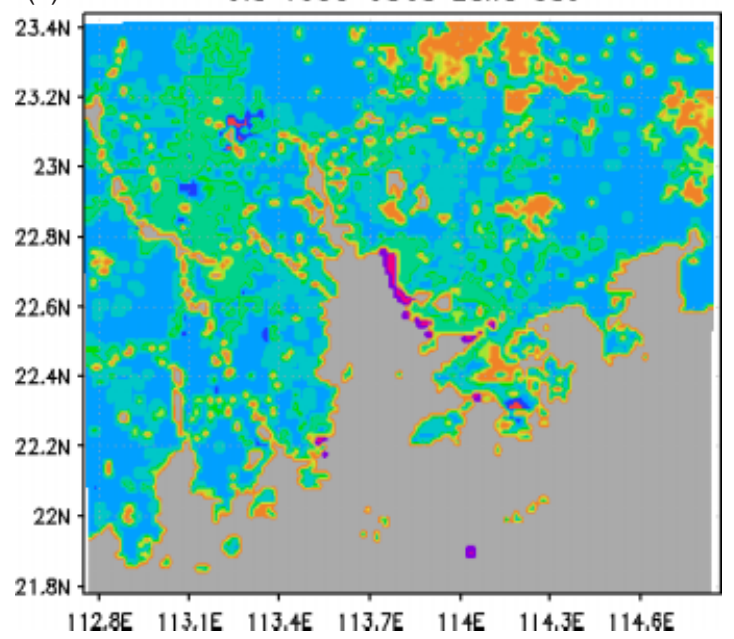

(d) New Land Use (more urbon areas)

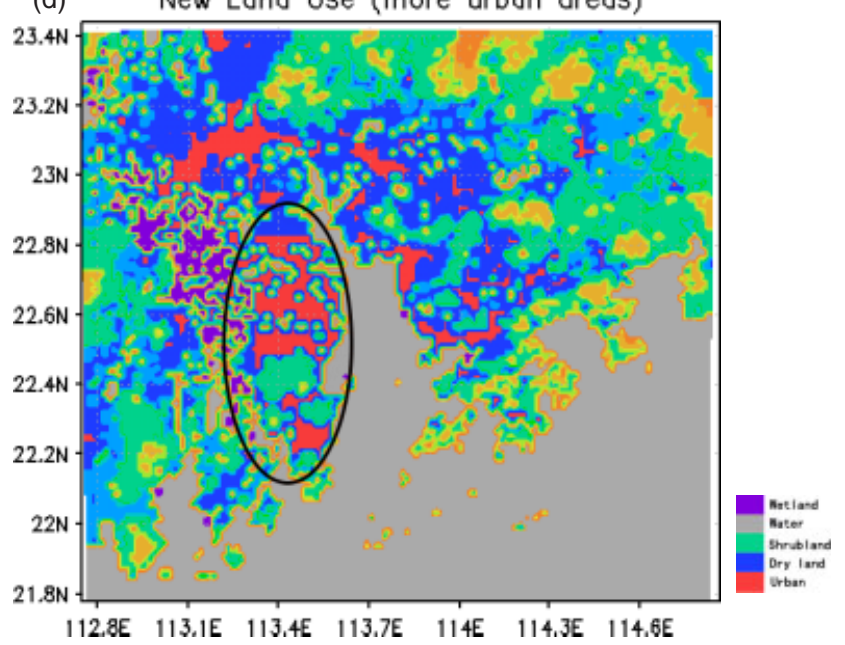

Figure 2. Land use map of D3 given by (a) new 2003 HKPD land use in CTRL, (b) old USGS land use in EXP_OLD, (c) new land use except over Shenzhen (circled) used in EXP_SHENZHEN, (d) more urban areas (in red colour) in the western coast of PRD (circled) used in EXP_URBAN. This figure is available in colour online at www.interscience.wiley.com/ijoc

the model. In the control experiment (CTRL), the model is run for 4 days from UTC 00 of 14 January to UTC 00 of 18 January 2004. This is the period in the middle of the winter so that the solar declination angle is close to the corresponding mean value in the season.

The design of CTRL is to obtain a converged circulation in the PRD region, i.e. the daily cycle or the diurnal variation of the simulated circulation does not vary significantly from day to day. The converged flow field driven by the seasonal mean FNL data is considered in this study as the mean circulation for the season. It has been shown in a number of trial runs that it is not easy to obtain a converged simulation of the relatively chaotic precipitation field (or other condensational processes), and thus the converged flow field is also not easy to obtain due to the effects of heat release associated with the precipitation. To obtain the converged flow field, fake dry runs with no cumulus parameterizations are used in the present study. Other physics parameterizations are chosen following Lo et al. (2007), in which the LSB circulation in the PRD region has been successfully simulated. In all the three domains, the NCEP medium-range forecast (MRF) PBL scheme (Hong and Pan, 1996) and the rapid radiative transfer model (Mlawer et al., 1997) combined with the cloud radiation shortwave scheme are used.

\subsection{Model validation}

In the 96-h simulation of CTRL, the first $48 \mathrm{~h}$ are considered as the spin-up time for the model. The same simulated surface wind and temperature fields in D3 on Day 3 and Day 4 of CTRL (Figure 3) suggest that converged circulation of the PRD region can be attained in the third day of the simulation. Therefore, in the sensitivity experiments described in the Section 3, the models were run for 3 days and the discussion will focus on the Day 3 model results. To investigate whether CTRL can successfully simulate the seasonal mean large-scale wind field, the daily mean wind in D1 of CTRL on Day 3 (Figure 4(b)) is compared with the FNL data averaged for winter 2003/2004 (Figure 4(a)). It can be observed from Figure 4 that CTRL is capable of reproducing the season's mean large-scale wind parameters for both 

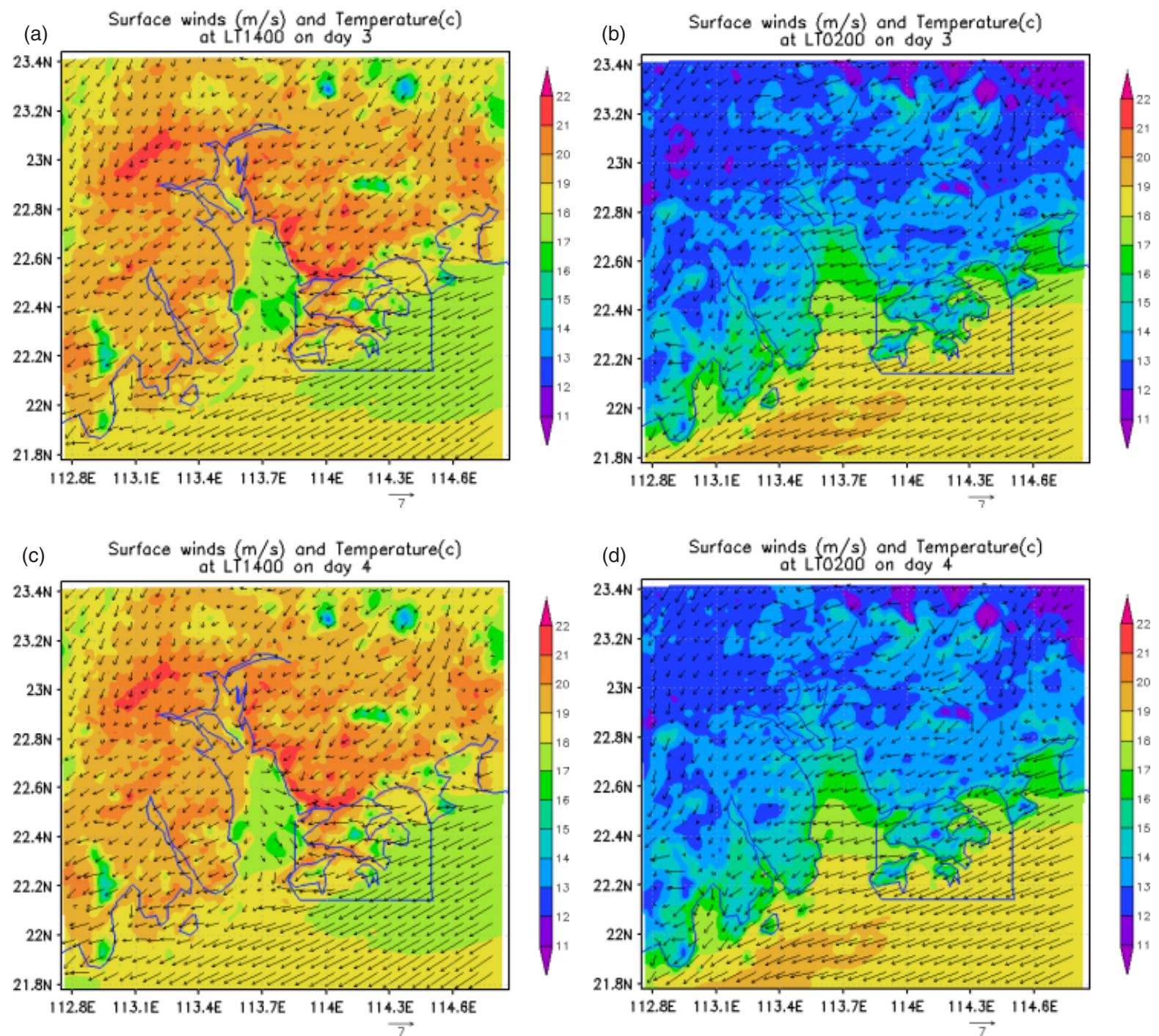

Figure 3. Surface wind and temperature fields in Domain 3 on Day 3 and Day 4 of the control experiment. (a),(c) at LT 1400; (b),(d) at LT 0200. This figure is available in colour online at www.interscience.wiley.com/ijoc

direction and speed. The prevailing wind direction is northeasterly, and the wind speed is larger over the ocean at a magnitude of $10 \mathrm{~m} \mathrm{~s}^{-1}$. In addition to successfully simulating the synoptic wind field, Figure 4(b) shows that CTRL may also simulate some smaller scale regional circulations over the land surface due to topography. In addition to simulating well the surface field, Figure 4(c) suggests that the CTRL is also capable of reproducing the vertical variation of the horizontal wind averaged over the PRD region for the winter 2003/2004.

Although CTRL can simulate well the large-scale wind field, the small-scale circulation in D3 should also be validated to see if the model is capable of simulating the mean diurnal variation of the regional wind field over the PRD region during the 2003/2004 winter. However, the data for validation is generally not available because weather stations are sparse in the region. One way to obtain the climatology of the wind field over such a small scale is to perform numerical simulations. However, simulating the small-scale flow field for the time scale of one year is very expensive and therefore simulation data is rare. Yim et al. (2007; YIM2007 hereafter) used the MM5 to develop a highresolution wind map for complex terrain to investigate the potential of using wind energy in Hong Kong. In their study, hourly wind fields were simulated for one year from 2003 to 2004 by MM5 with four nested meshes from $40.5 \mathrm{~km}$ down to $1.5 \mathrm{~km}$ horizontal resolution using the 2003 HKPD land use data. Their simulation results were shown to be good by comparing with the data of local weather stations. In this study, we used the YIM2007 simulation data averaged in the winter 2003/2004 to validate the results of CTRL. It can be observed from Figure 5 that CTRL can successfully simulate the basic features of the diurnal variation of the surface wind and temperature fields in the PRD region although the LSBs are generally stronger in CTRL. One possible reason is that in the fake dry run of CTRL the radiation effects of clouds are absent and the ground surface may receive more solar radiation compared with the more realistic simulations of YIM2007. It is also worth noting that the flows over the land surface in YIM2007 data are 
(a) Daliy mean surface winds(m/s) (FNL) in winter

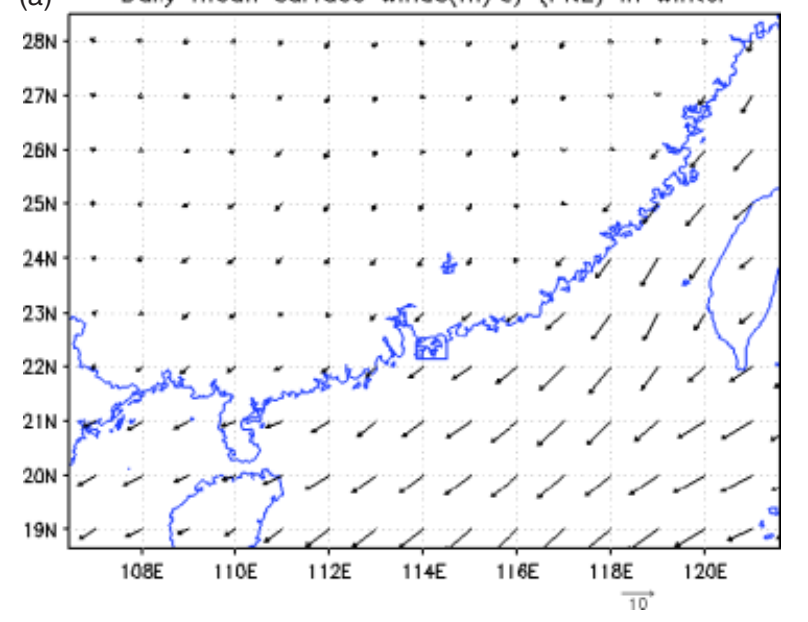

(b) Daily mean surface winds(m/s)(CTRL D1) on day3

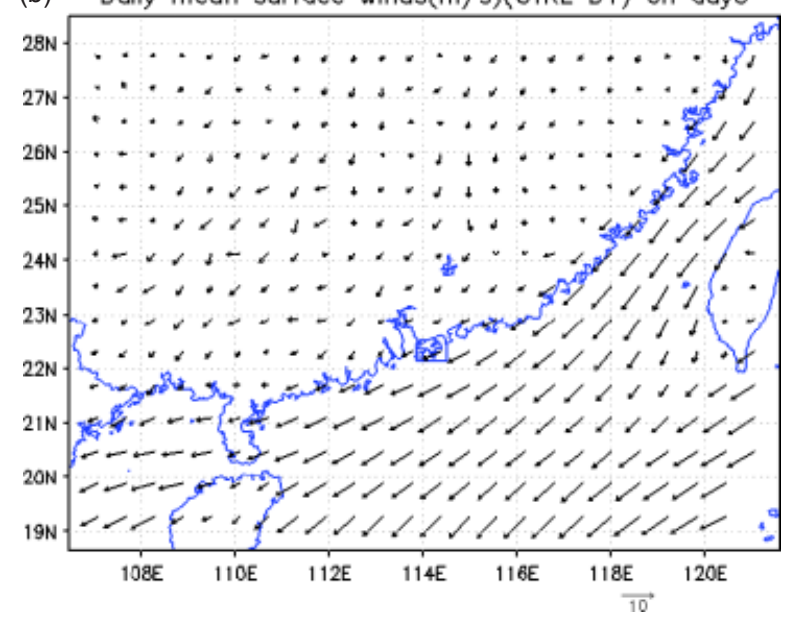

(c) Daily-mean horizontol wind vectors $(\mathrm{m} / \mathrm{s})$ in winter

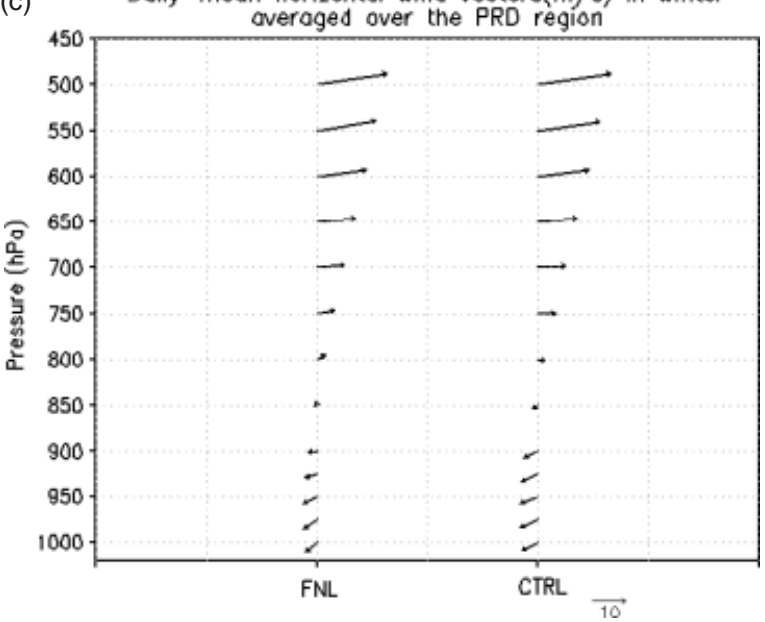

Figure 4. Daily-mean surface wind fields in D1 for (a) FNL data averaged for winter 2003/2004, and (b) control experiment on day 3. (c) shows the corresponding vertical profiles of horizontal velocity vectors averaged over the Pearl River Delta region $\left(112.5-115^{\circ} \mathrm{E}\right.$, $\left.21.5-23.5^{\circ} \mathrm{N}\right)$. This figure is available in colour online at www. interscience.wiley.com/ijoc

much smoother than those in CTRL (cf. Figure 5(a), (c), (e) and (g) and Figure 5(b), (d), (f) and (h)), since the less organized flows related to the terrain are generally smoothed out in the 3-month averaged data of YIM2007. It can be observed from Figure 5 that at LT 0800 and LT 0200 , the land surface is cooler than the ocean and so the land breezes (LBs) are well developed over the Pearl River Estuary. In the afternoon (LT 1400), CTRL shows a prominent sea breeze (SB) developing along the eastern coast of the PRD (Figure 5(d)) because of the increase in surface temperature over the land surface. This northwesterly sea breeze towards the eastern coast of the PRD is not very obvious in the YIM2007 data (Figure 5(c)). However, the anomalous (local times daily mean) surface wind field (Figure 6) shows that CTRL is capable of reproducing well the diurnal variation of the LSBs in the region. In particular, the anomalous westerly sea breeze towards the eastern coast of the PRD at LT 1400 is clearly shown in both the results of CTRL and YIM2007 (Figure 6(c) and (d)). This results in a convergence zone in the eastern PRD particularly in the west of Hong Kong, which may reduce the dispersion of pollutants in Hong Kong, thereby enhancing the air pollution there. More details about this afternoon convergence zone will be further discussed in the next section.

The relatively weak anomalous easterly and northeasterly winds over the PRD estuary at night (LT 0200) and morning (LT 0800) can also be captured by CTRL (Figure 6). However, the anomalous surface wind field at LT 2000 simulated by CTRL is relatively poor ( $c f$. Figure 6(e) and (f)) compared with the other three time periods. A possible explanation for this discrepancy is that LT 2000 is in the transition period when SBs start changing to LBs. The complex wind field can be seen in CTRL but it is smoothed out in YIM2007 data. In CTRL, the LBs are strong near the western bank of the Pearl River Estuary but are weak in the eastern PRD (Figure 6(f)). These results are similar to those obtained by Buckley and Kurzeja (1997) and Ding et al. (2004).

In conclusion, although the surface wind fields from CTRL and YIM2007 have some differences, the diurnal variations of the wind and temperature fields show similar patterns. The results from CTRL suggest that the model set-up in this study could capture the basic features and diurnal variation of the LSB circulation in the PRD region during the 2003/2004 winter.

\section{Sensitivity experiments}

\subsection{Description of the experiments}

Three sensitivity experiments were carried out with the idealized model described in Section 2. The model configurations in all three experiments are the same as in CTRL except with different land use patterns over the PRD region to investigate the effects of urbanization in the region.

In the first sensitivity experiment EXP_OLD, the USGS land use data of 1993 is applied (Figure 2(b)). This dataset is derived from the 1-km Advanced Very High Resolution Radiometer (AVHRR) data in a 12-month 
period spanning from April 1992 to March 1993 (Guo and Chen, 1994; Liu et al., 2006). Comparing the land use patterns in CTRL and EXP_OLD ( $c f$. Figure 2(a) and (b)), we can see that in 1993 there were fewer urban areas (red colour) and most regions were cropland. However, in 2003 the urban area had increased to about $22 \%$ of the whole land area. Most of the cities in the PRD had not been highly urbanized and were small towns in the USGS land use data of 1993. This sensitivity experiment is motivated by previous studies, which suggested this urbanization might change the local meteorological conditions in the PRD region (Fung et al., 2005; Lam et al., 2006; Lo et al., 2006) and that more urbanization in the eastern PRD might induce stronger local SBs (Lo et al., 2006).

In the second sensitivity experiment EXP_ SHENZHEN, the 2003 HKPD land use data is still applied over the PRD region as in CTRL except that the urban land use for the city Shenzhen is replaced by shrubland (cf. Figure 2(a) and (c)). As shown in Figure 1(b),
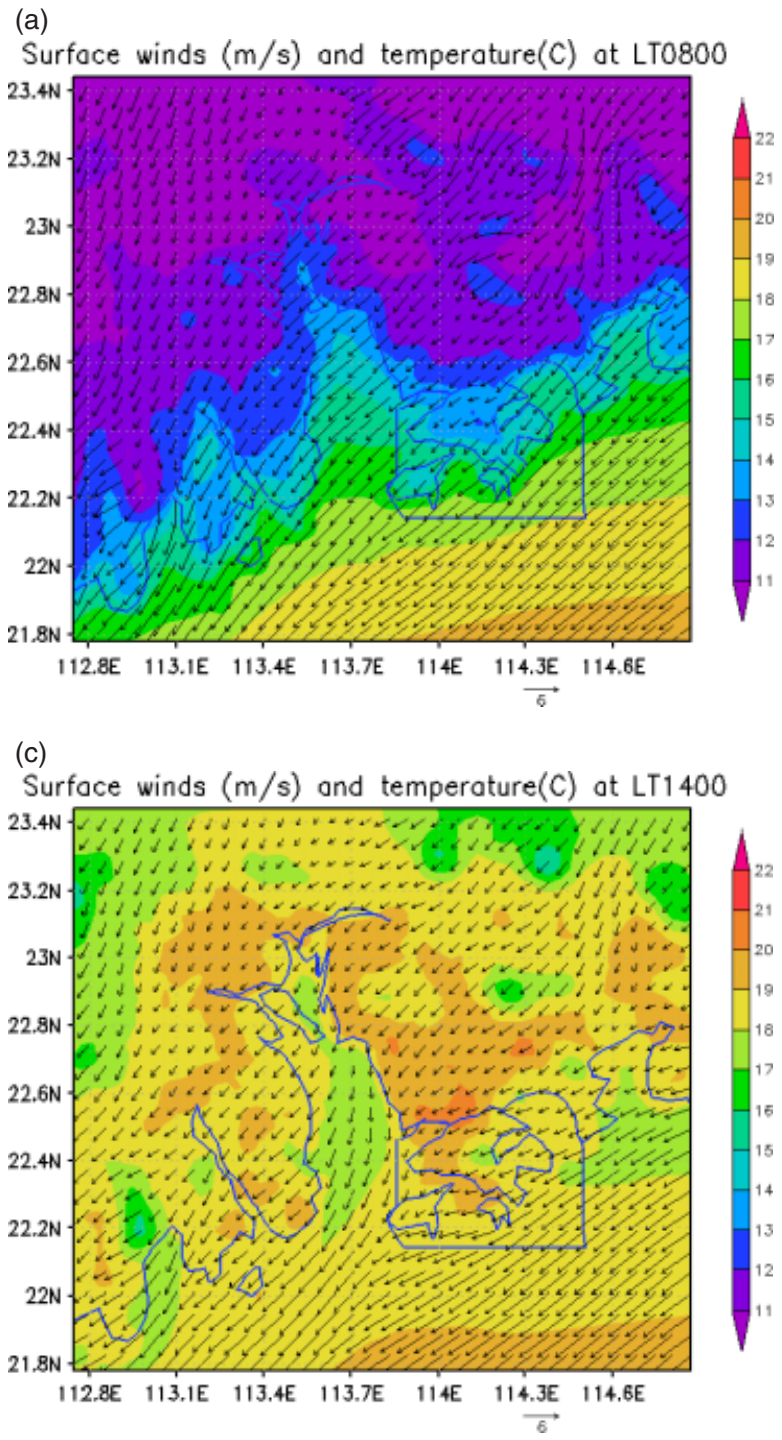

Shenzhen is a major city located on the eastern coast of the PRD and neighbouring north Hong Kong. The design of this sensitivity experiment aims to investigate whether the heat island effect associated with the rapid development of this major city in the past two decades has affected the local circulation in Hong Kong.

The third sensitivity experiment EXP_URBAN is designed to investigate the effects of a possible future urbanization scenario in the PRD region on the regional circulation. In this experiment more urban areas are added to the western coastal region of the PRD. At present, these areas are primarily farmland (cf. Figure 2(a) and (d)). To simulate this scenario, land uses of regions with terrain lower than $50 \mathrm{~m}$ within the region $\left(113.3-113.6^{\circ} \mathrm{E}\right.$, $22.18-22.83^{\circ} \mathrm{N}$ ) are converted to urban area.

\subsection{Results of the experiments}

In general, the effects of urbanization have the largest impact during the afternoon period when urban areas are heated up rapidly by the maximum solar radiation
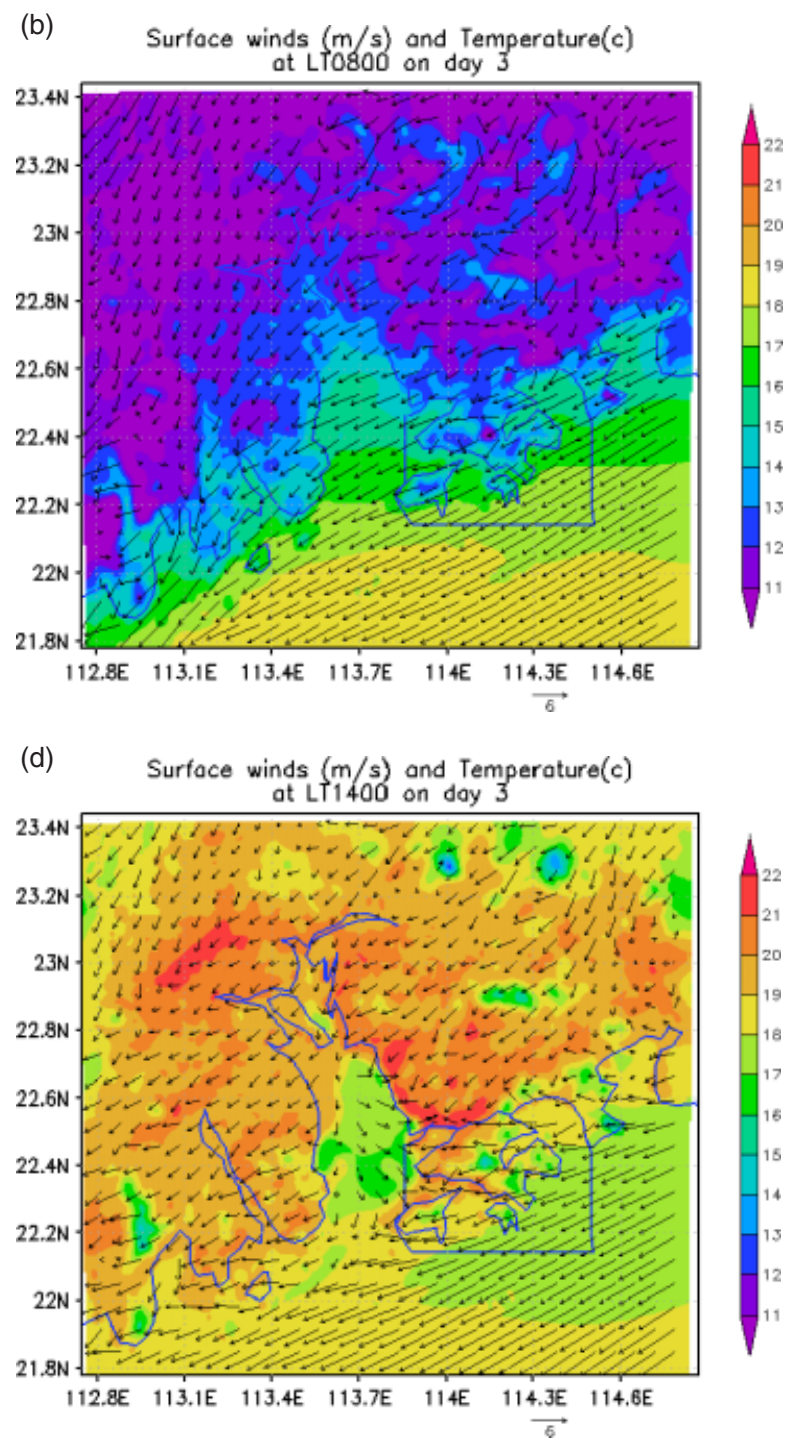

Figure 5. Surface wind and temperature fields (LT 08, 1400, 20, 02) in D3. (a), (c), (e), (g) are from YIM2007 data. (b), (d), (f), (h) are from the control experiment on day 3. This figure is available in colour online at www.interscience.wiley.com/ijoc 
(e)

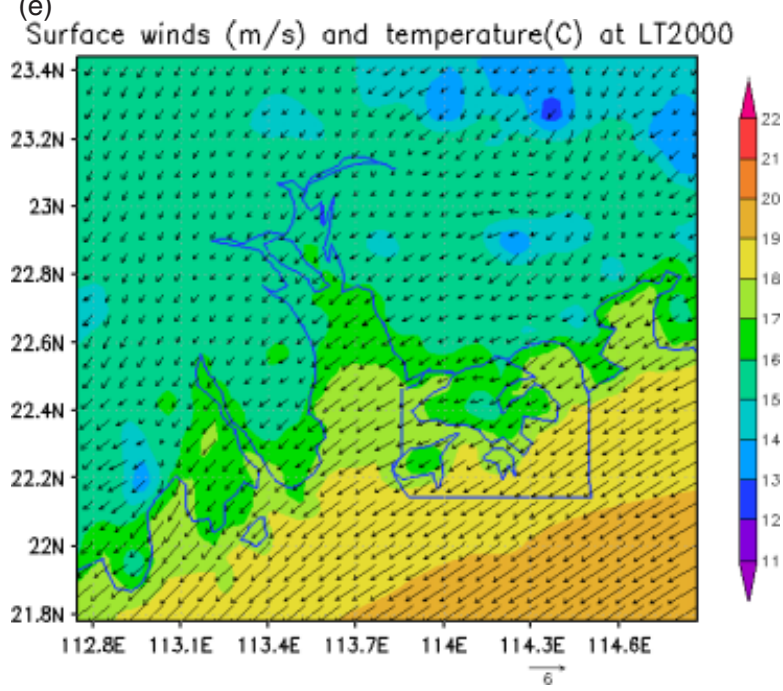

(g)
Surfoce winds $(\mathrm{m} / \mathrm{s})$ and temperature $(\mathrm{C})$ at LTO200

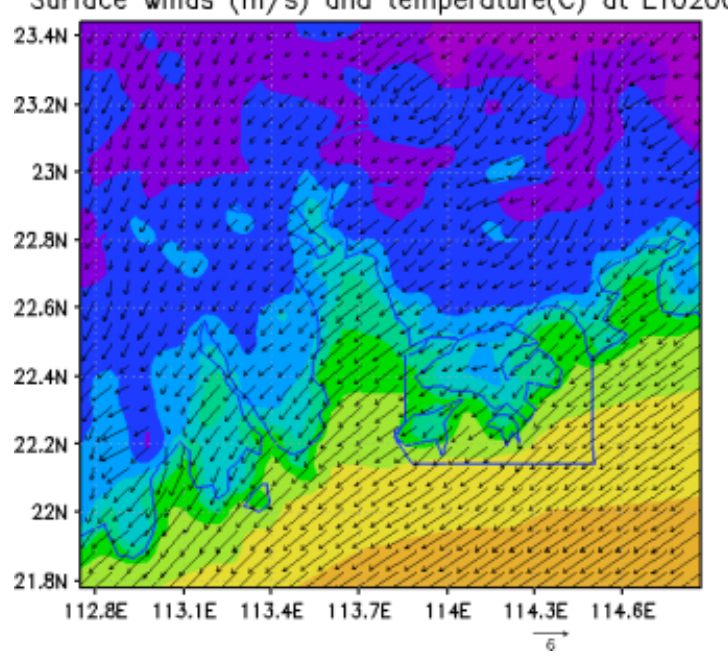

(f) Surface winds $(\mathrm{m} / \mathrm{s})$ and Temperature(c)

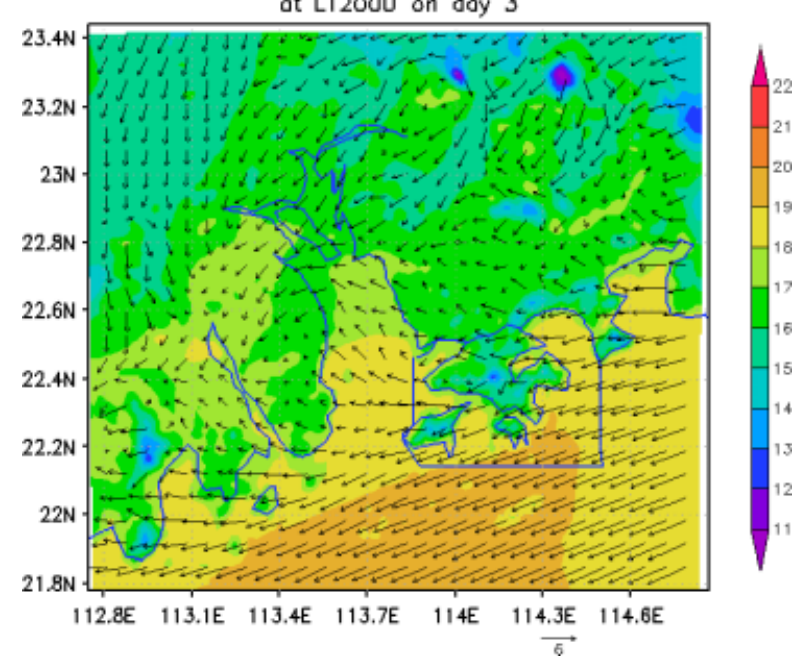

(h) Surface winds $(\mathrm{m} / \mathrm{s})$ and Temperature(c) at LTO200 on day 3

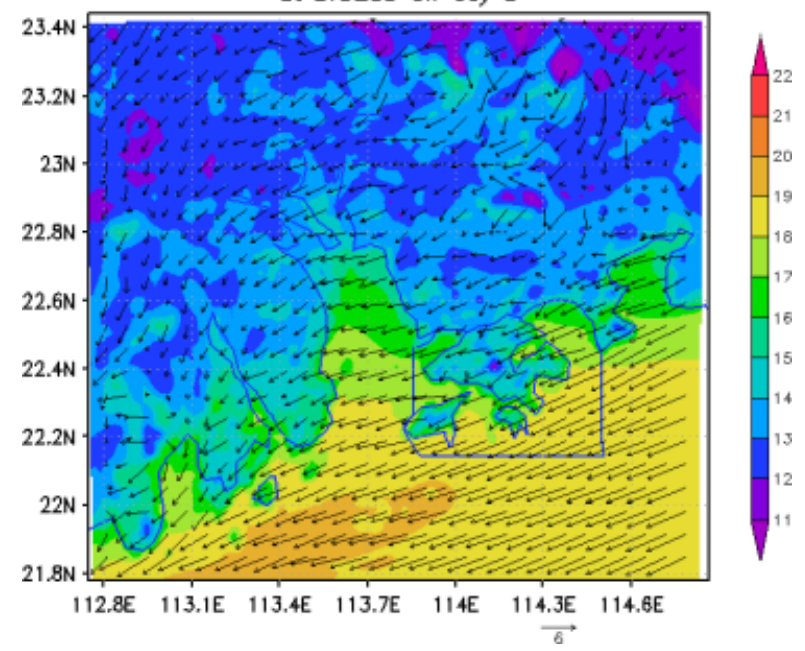

Figure 5. (Continued).

at mid-day (Lo et al., 2007). It has been discussed previously that in CTRL a strong westerly SB towards the eastern coast of the PRD can be observed at LT 1400 (Figures 5(d) and 6(d)). In this study we focus on the effects of different scenarios of urbanization in the three sensitivity experiments on the LSBs in this afternoon period. In fact, the results of the sensitivity experiments indicate that the largest responses also occur at LT 1400, while the corresponding responses at other time periods are much smaller. Thus, the discussion in this study will be focused on the results of the sensitivity experiments at LT 1400. However, the corresponding results at LT 0200 will also be shown to let the readers get a better picture about the effects of urbanization on the diurnal cycle.

The differences in surface wind fields and lowlevel divergences averaged for the three lowest levels below $50 \mathrm{~m}$ between experiment EXP_OLD and CTRL (Figure 7) show that more urban areas over the PRD region in 2003 (CTRL) may enhance the westerly SBs in the PRD at LT 1400 and result in the maximum convergence to the west of Hong Kong (Figure 7(a)).
However, at LT 0200 when the LBs develop over the Pearl River estuary, there are no obvious differences between CTRL and experiment EXP_OLD. This strong low-level westerly and convergence at LT 1400 may have adverse effects on the dispersion of pollutants out of Hong Kong and so may worsen the pollution problems there. It can be observed from the time variation of the area-averaged low level convergence over the Hong Kong region $\left(113.8-114.4^{\circ} \mathrm{E}, 22.18-22.55^{\circ} \mathrm{N}\right)$ in Figure 13 that the convergence starts to increase from about LT 0800 and attains the maximum value at about LT 1400 . The higher proportion of urban areas in CTRL may help to increase the convergence from LT 1100 to LT 1600 ( $c f$. CTRL and EXP_OLD in Figure 13). After LT 1700 the effect is negligible.

The stronger westerly SB at LT 1400 in CTRL may be due to the prominent development of urban areas in the eastern PRD, particularly in the coastal regions of the eastern PRD such as Shenzhen ( $c f$. Figure 2(a) and (b)). In fact, the corresponding results of experiment EXP_SHENZHEN at LT 1400 (Figure 8(a)) 
are similar to those in experiment EXP_OLD. The increased westerly winds and convergence can also be seen clearly in the western part of Hong Kong. The time variation of the convergence in Hong Kong in EXP_SHENZHEN is also similar to that of EXP_OLD and CTRL, with the maximum convergence occurring at LT 1400 (Figure 13), although the magnitude is slightly lower when compared to EXP_OLD. The similarity of the results in EXP_OLD and EXP_SHENZHEN is interesting, because this suggests that compared to the development of other cities in the PRD region the urbanization of Shenzhen plays a dominant role in modifying the afternoon SBs in the region. This is a slightly surprising result because comparing the land use in EXP_OLD and CTRL ( $c f$. Figure 2(a) and (b)), the urbanization of the highly populated city Guangzhou is prominent but its effect on the afternoon SB over the PRD region is not significant. This is in agreement with the results of our ongoing research, in which numerical experiments show that the urban heat island effect of

(a) Anomalous (LTO800-daily mean)
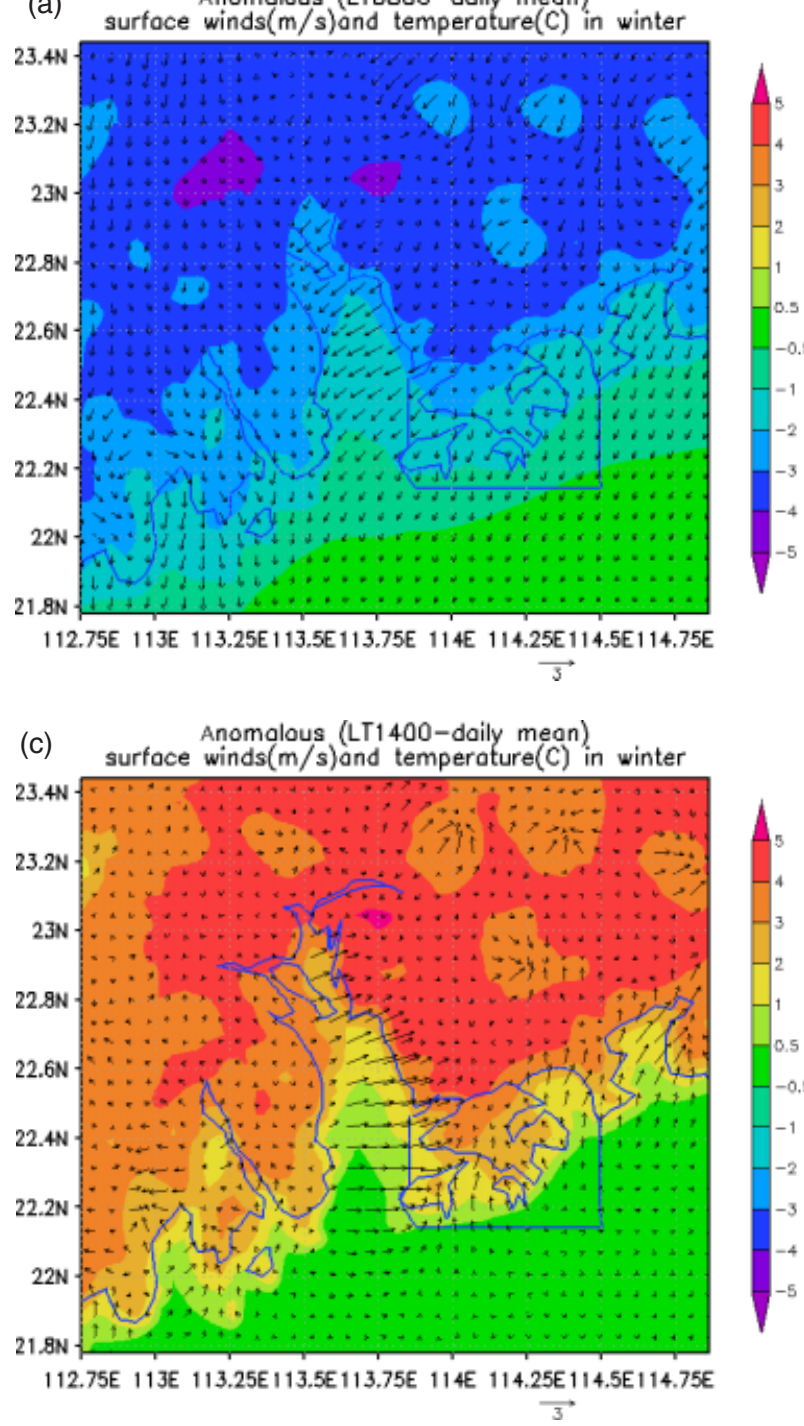

Guangzhou has a negligible effect to the LSB circulation in the PRD region.

The anomalous westerly SB at LT 1400 between CTRL and EXP_SHENZHEN is likely related to the increase in surface temperature over Shenzhen due to urbanization (Figure 10(a)). It is worth noting that in this case in the PRD region the increase in surface temperature over Shenzhen does not enhance the convergent flow locally but at a southern location to the west of Hong Kong. In addition, the stronger westerly winds may result in a lower sea surface temperature near the western coast of Hong Kong (Figure 10(a)) basically due to the enhanced surface heat exchange between the sea surface and the overlying SB.

In EXP_URBAN, urban areas are substantially increased along the western coast of the PRD (Figure 2(d)). The difference in urban areas between EXP_URBAN and CTRL is much larger than that between EXP SHENZHEN and CTRL. Therefore, it is rather surprising that the afternoon SB in the PRD is not significantly

(b) Anomalous (LTO800-daily mean)
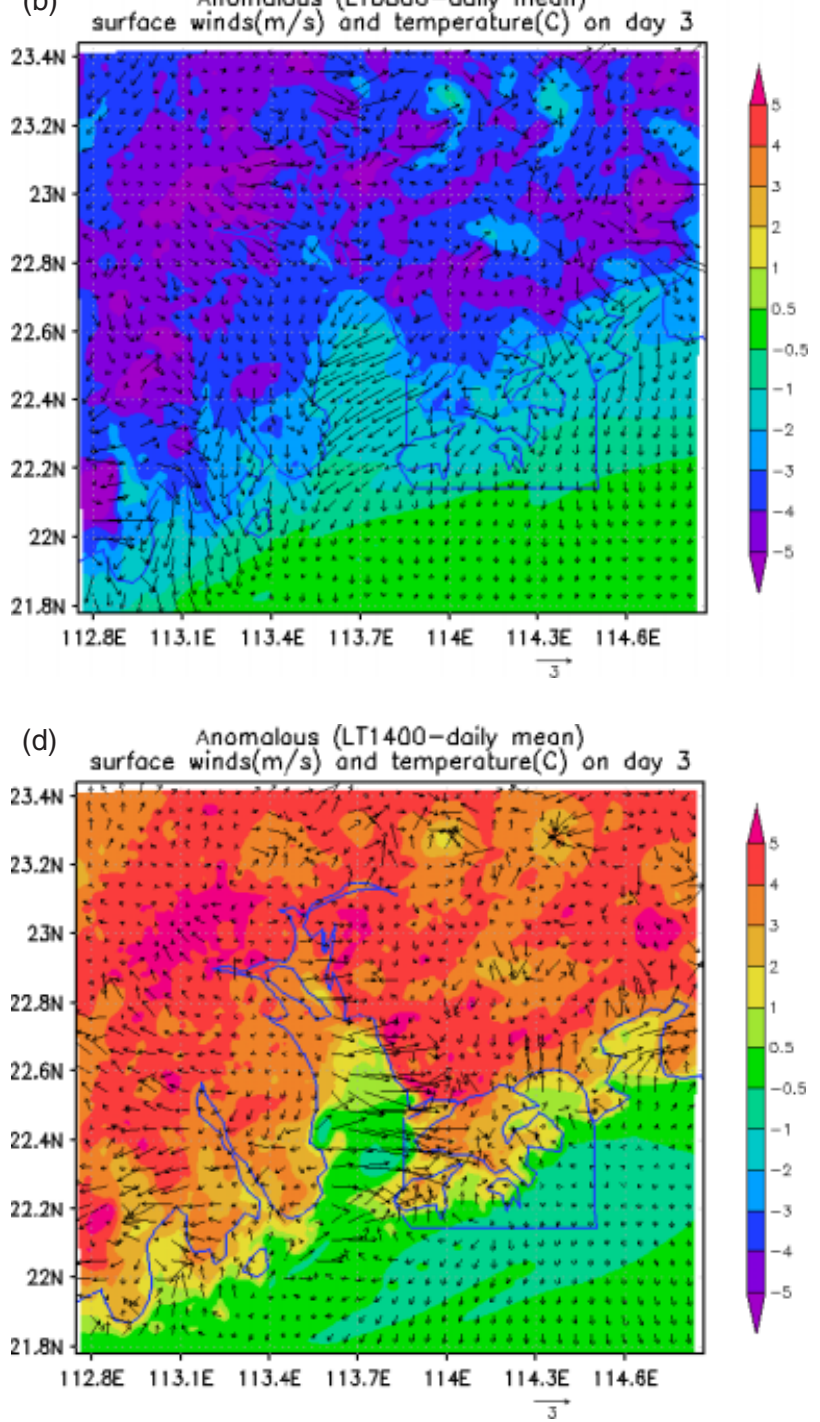

Figure 6. As in Figure 5, but for the anomalous (local times daily mean) surface wind and temperature fields. This figure is available in colour online at www.interscience.wiley.com/ijoc 

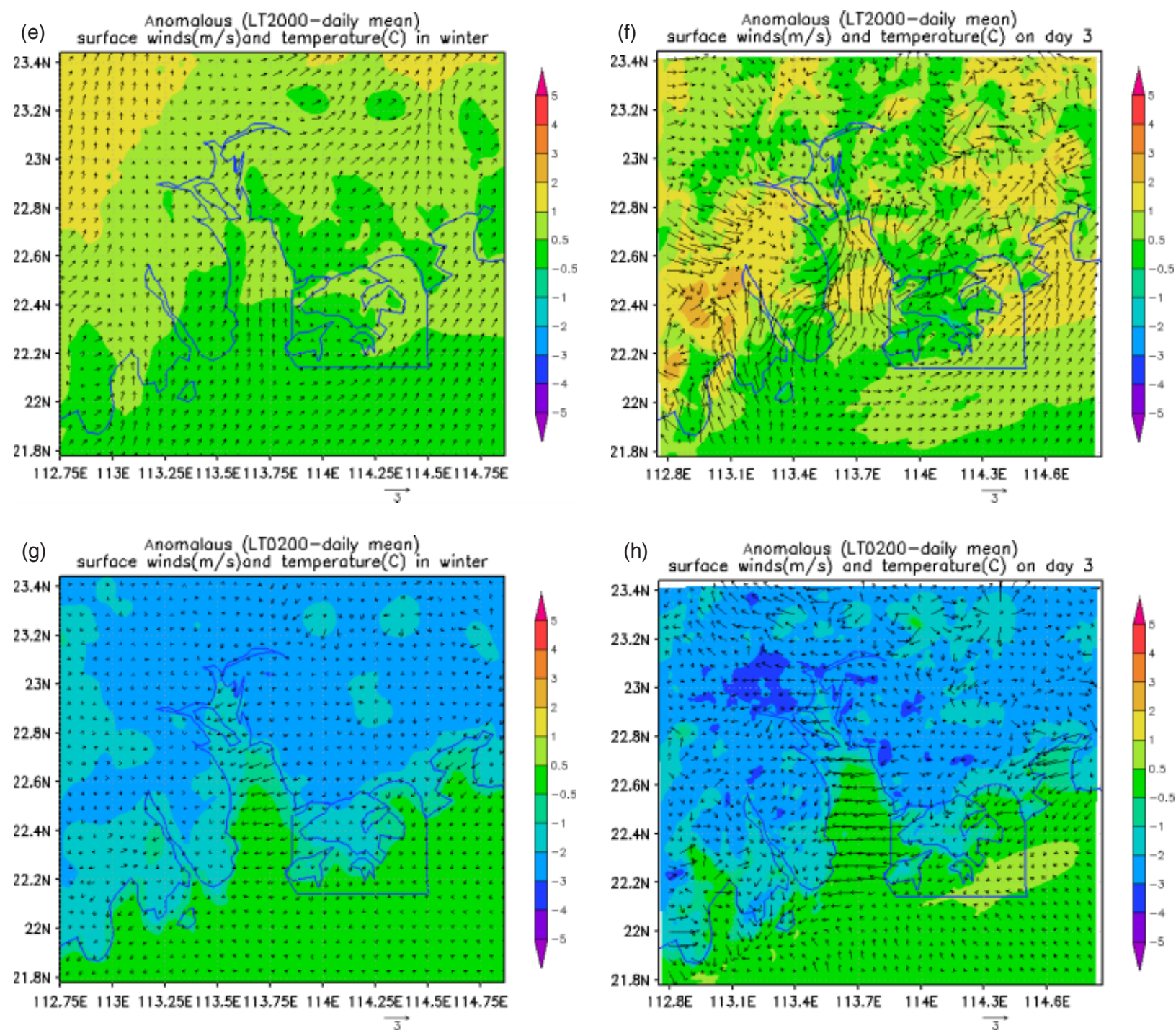

(h) Anomalous (LTO200-daily mean)

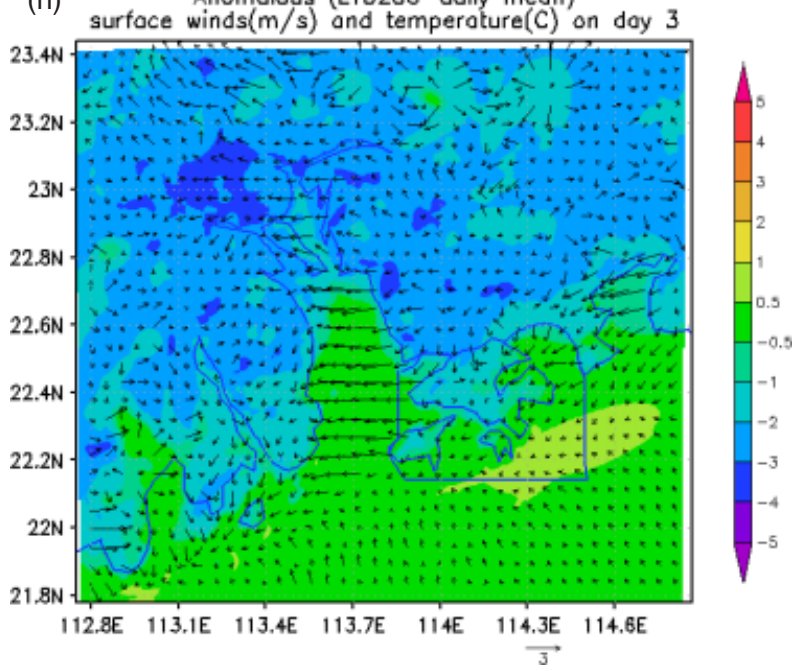

Figure 6. (Continued).

changed in EXP_URBAN (Figure 9(a)). It can also be observed from the time series of the convergence in Hong Kong (Figure 13) that EXP_URBAN has a negligible effect on the low-level convergence at Hong Kong at all times, as it is very similar to that of CTRL. Nevertheless, the heat island effect due to the substantial increase in urban areas in EXP_URBAN can still be identified over the western PRD in early afternoon, where significant anomalous convergence associated with the anomalous northwesterly and southeasterly flows can be observed in the western PRD (Figure 9(a)). This convergence is likely caused by the increase in surface temperature over the western PRD due to the increase in urban areas (Figure 10(b)). The results from EXP_URBAN indicate that the effects of urbanization in the western coast of the PRD region are relatively local, and may only worsen the local air pollution problem due to the increase in low-level convergence. Similar to the previous two experiments, the increase in urbanization over the western PRD does not have significant effect on the LSB circulation over the PRD region at LT 0200 (Figure 9(b)).
As has been discussed above, changes in urban areas in the PRD region in EXP_OLD and EXP_SHENZHEN may significantly change the early afternoon convergence in the west of Hong Kong due to the changes in the westerly SBs along the eastern coast of the PRD. The changes in the early afternoon westerly SBs can be further examined from the vertical circulations of the four experiments utilizing cross sections through Hong Kong at LT 1400. It can be observed from Figure 11(a) that some closed circulations are well developed near the coastal regions in CTRL and the most prominent one is located over the Pearl River Estuary $\left(113.6-113.9^{\circ} \mathrm{E}\right)$. Near the western boundary of Hong Kong $\left(\sim 113.9^{\circ} \mathrm{E}\right)$, the upward flow may attain up to approximately $1000 \mathrm{~m}$ (PBL height) and the maximum vertical velocity can reach $0.25 \mathrm{~m} \mathrm{~s}^{-1}$. On the other hand, downward motion is occurring over the Pearl River Estuary. This loop of vertical circulation is completed by the strong westerly flow over the Pearl River Estuary, which is largely confined to an altitude below $200 \mathrm{~m}$. 
Differences in surface wind fields and low level divergence (a) at LT1400 between CTRL and EXP_OLD

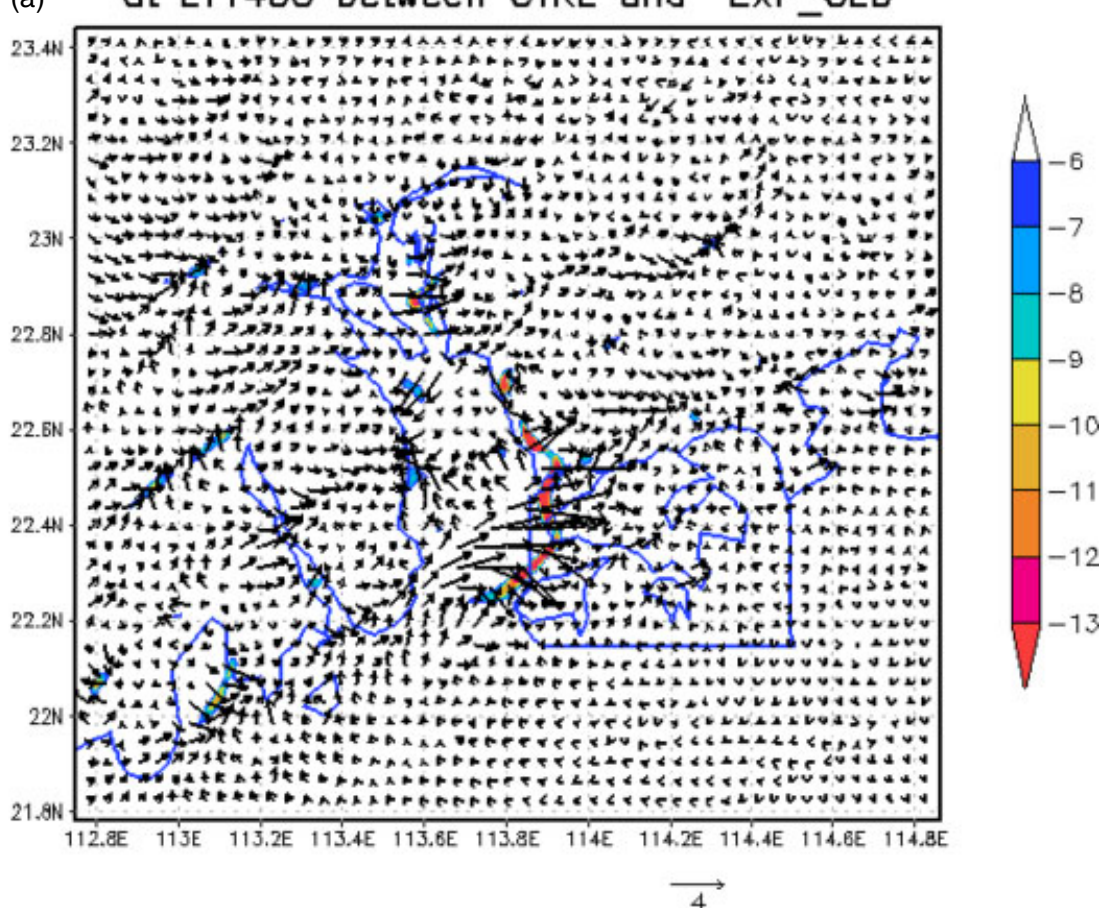

Differences in surface wind fields and low level divergence

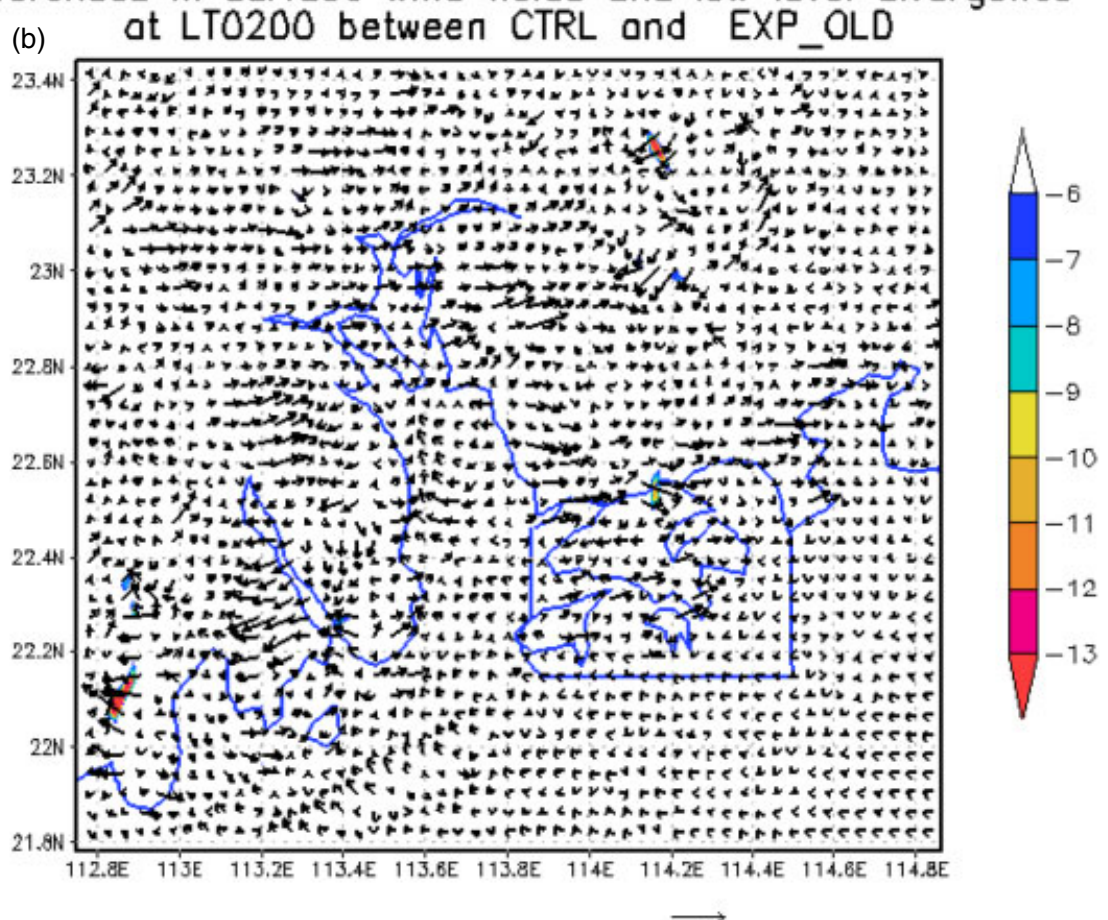

Figure 7. Differences (CTRL - experiments) in surface wind fields and low-level divergences (shadings, $10^{-4} \mathrm{~s}^{-1}$, averaged for the three lowest levels below $50 \mathrm{~m}$ ) between experiment EXP_OLD (old land use) and CTRL at (a) LT 1400, (b) LT 0200. This figure is available in colour online at www.interscience.wiley.com/ijoc

In experiment EXP_OLD, the vertical circulation over the PRD discussed in the last paragraph is generally absent (Figure 11(b)). As a result, the westerly flow over the Pearl River Estuary is replaced by the prevailing easterly winds, and the upward vertical velocity near the western boundary of Hong Kong is reduced to about
$0.05 \mathrm{~m} \mathrm{~s}^{-1}$. The corresponding difference in vertical circulations between CTRL and experiment EXP_OLD (Figure 12(a)) clearly shows that the substantial urbanization of the PRD region in 2003 of CTRL might lead to the increase in downward flows over the Pearl River Estuary, and stronger upward flows occur at the western boundary 


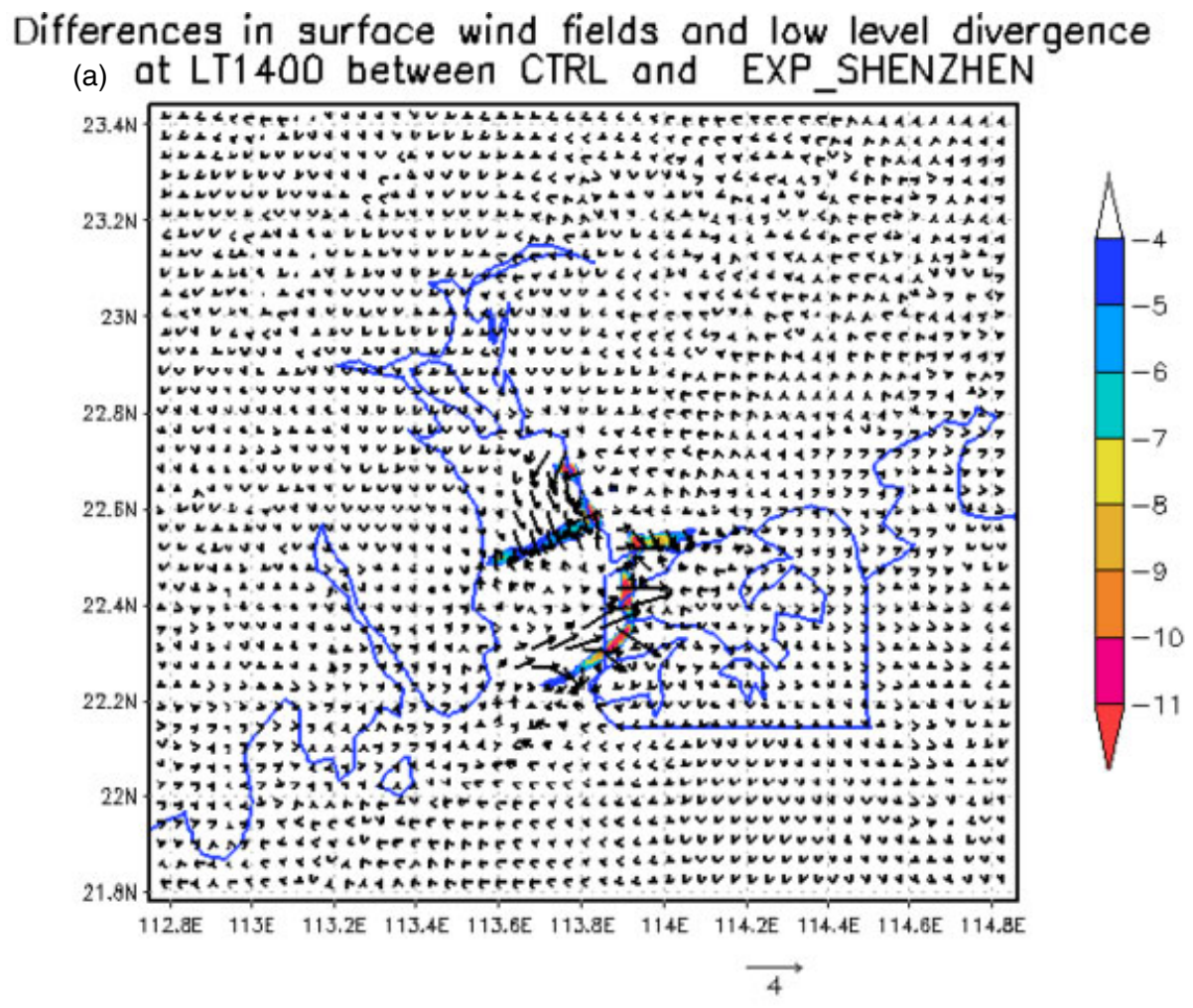

Differences in surface wind fields and low level divergence (b) at LTO200 between CTRL and EXP_SHENZHEN
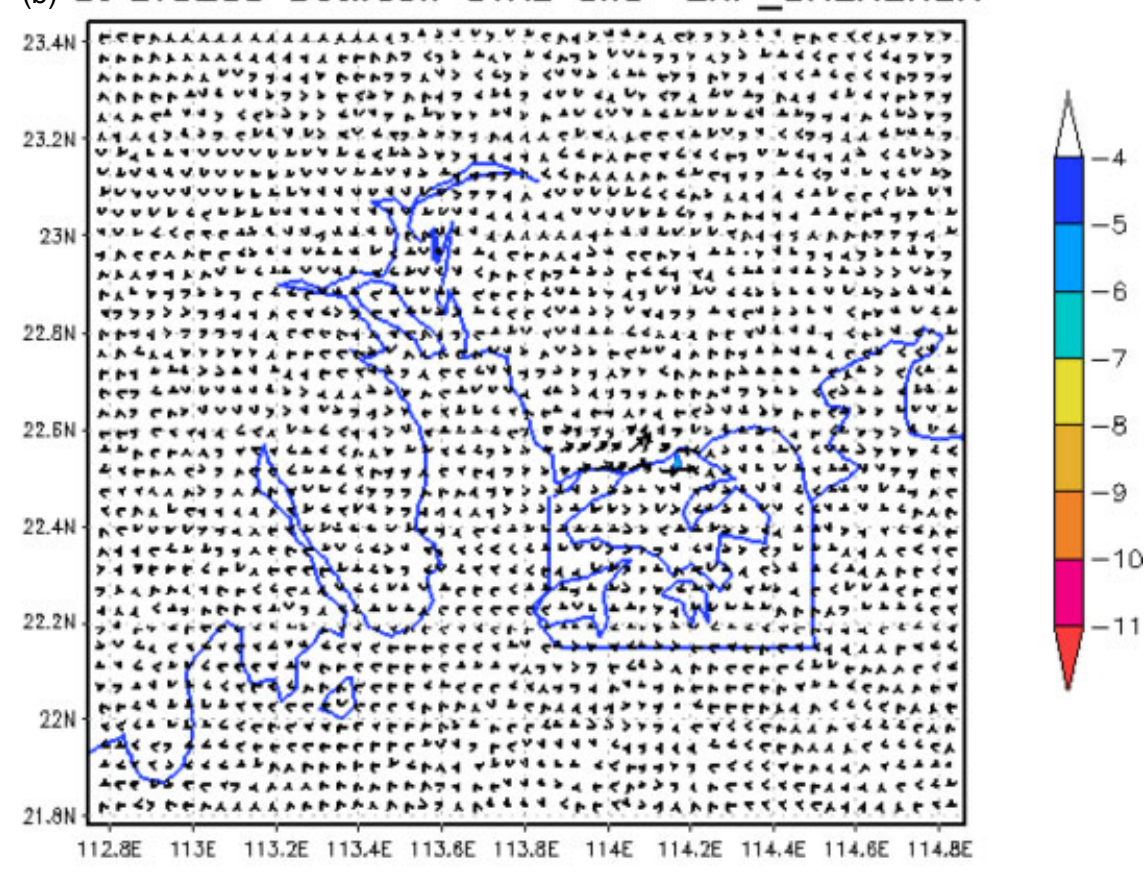

Figure 8. Same as Figure 7, but for experiment EXP_SHENZHEN (without Shenzhen). This figure is available in colour online at www.interscience.wiley.com/ijoc

of Hong Kong. This heat island circulation enhances the SB circulation, and this interaction may affect the cities near the eastern coast of the PRD.

The vertical cross section in EXP_SHENZHEN is similar to that in EXP_OLD ( $c f$. Figure 11(b) and (c)) and is consistent with the similar differences in surface wind fields at LT 1400 (Figures 7(a) and 8(a)). Without the development of Shenzhen, the afternoon westerly SB might also be replaced by the prevailing easterly wind (Figure 11(c)). The corresponding difference in vertical circulations (Figure 12(b)) indicates that the development of Shenzhen may also result in a small anomalous 
Differences in surface wind fields and low level divergence (a) at LT1400 between CTRL and EXP_URBAN

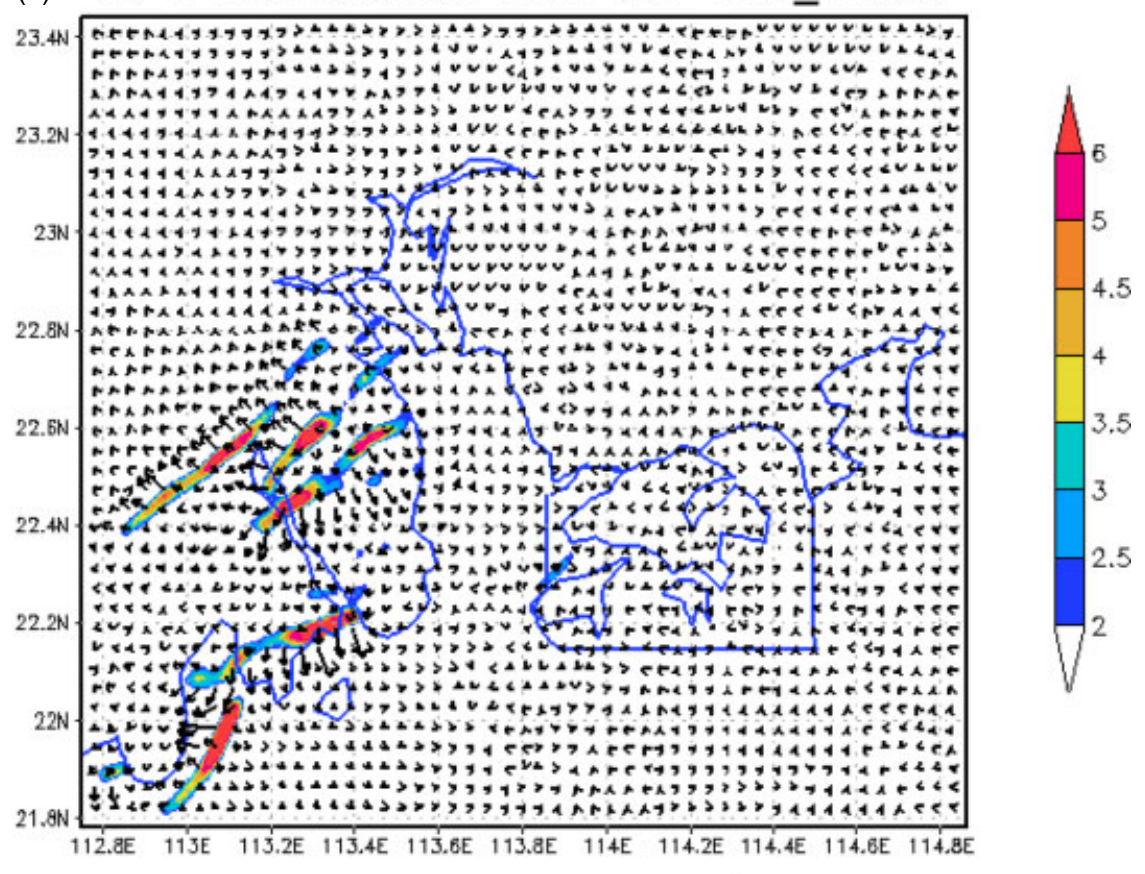

Differences in surface wind fields and low level divergence (b) at LTO200 between CTRL and EXP_URBAN

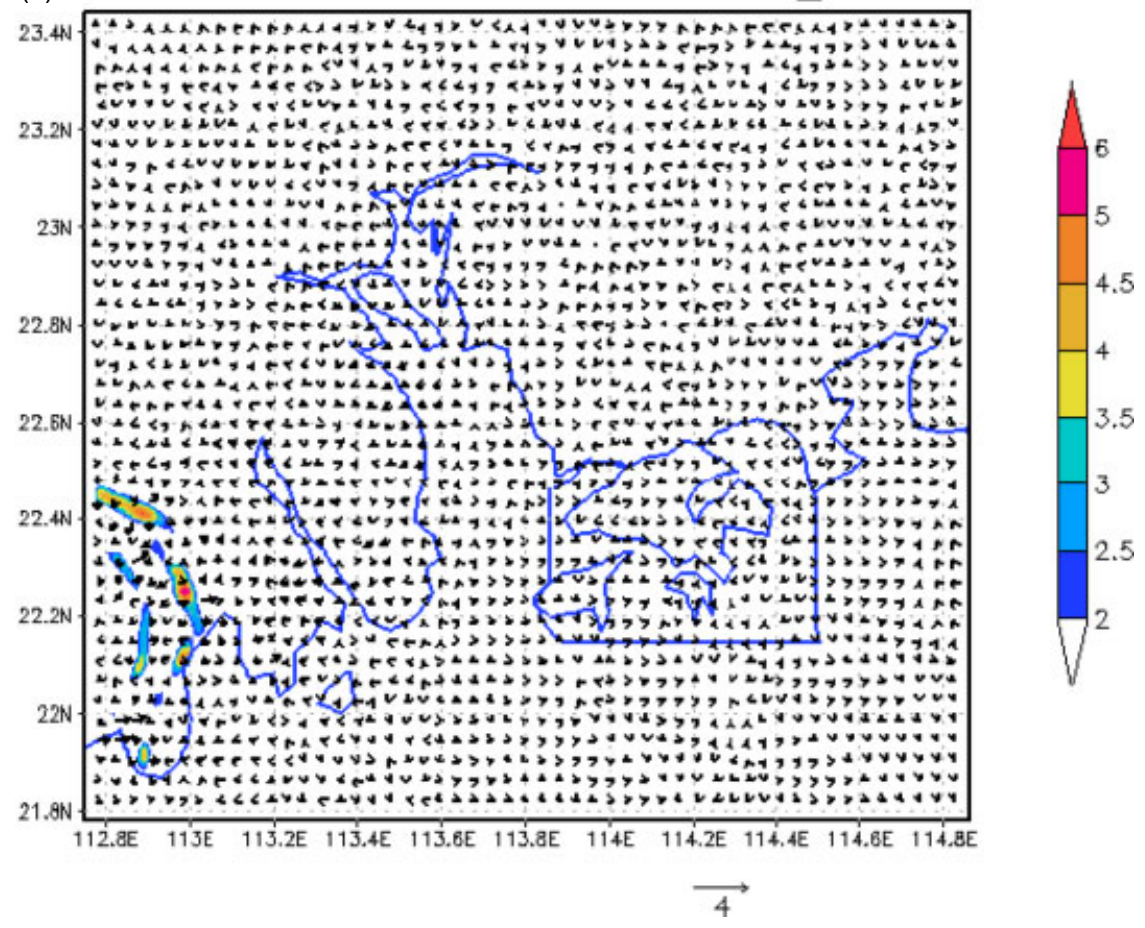

Figure 9. Same as Figure 7, but for experiment EXP_URBAN (more urban areas in the western coast of PRD). This figure is available in colour online at www.interscience.wiley.com/ijoc

vertical circulation which may enhance the downward flow and the westerly SBs in the eastern coast of PRD, increasing the upward motion near the western boundary of Hong Kong $\left(113.9^{\circ} \mathrm{E}\right)$. Again, the similarity in surface wind fields and vertical circulations of EXP_OLD and EXP_SHENZHEN suggests that the afternoon SB and low-level convergence towards the western boundary of Hong Kong in CTRL are primarily caused by the development of Shenzhen.

The corresponding vertical circulation in EXP_URBAN is very similar to that in CTRL (Figure 11(a) and (d)). This is consistent with the results shown in Figure 13 
(a) Differences in surfoce temperature(C)
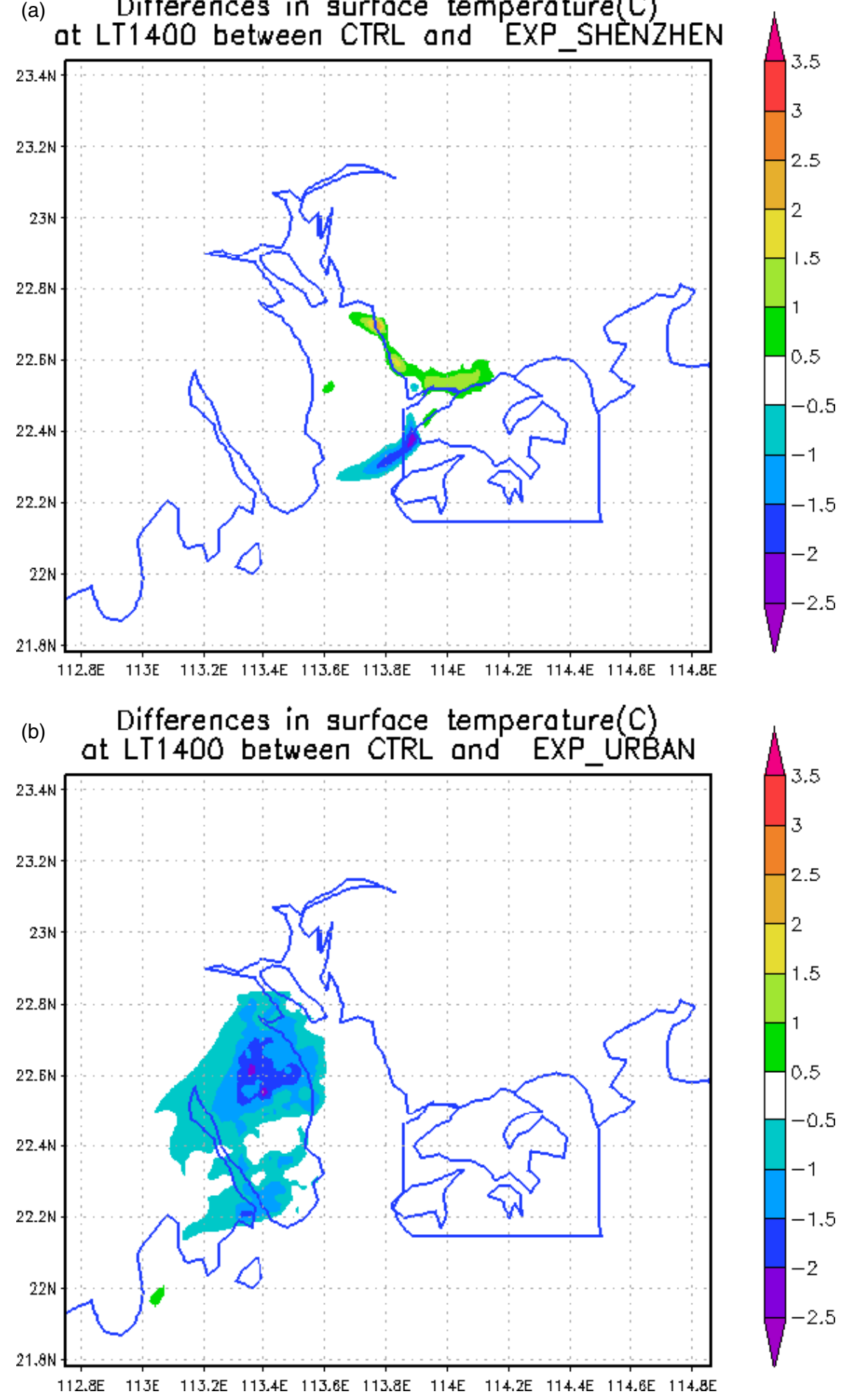

Figure 10. Differences (CTRL - experiments) in surface temperature fields at LT 1400 between CTRL and experiments (a) EXP_SHENZEHN, (b) EXP_URBAN. This figure is available in colour online at www.interscience.wiley.com/ijoc

and further suggests that an increase in urban areas over the western PRD does not significantly affect the vertical circulation in the eastern PRD.

\section{Concluding remarks}

The general effects of urbanization on the seasonal LSBs and the local circulation in the 2003/2004 winter have been studied using an idealized setting of the mesoscale meteorological model MM5. To avoid using a large amount of computing resources, an alternate approach to simulating the seasonal mean wind field is adopted in this study, in which the seasonal mean reanalysis data is used as the initial and boundary conditions to drive the model. The model has been shown to be capable of simulating well the basic feature and diurnal variation of the LSBs in the PRD region for this season. 

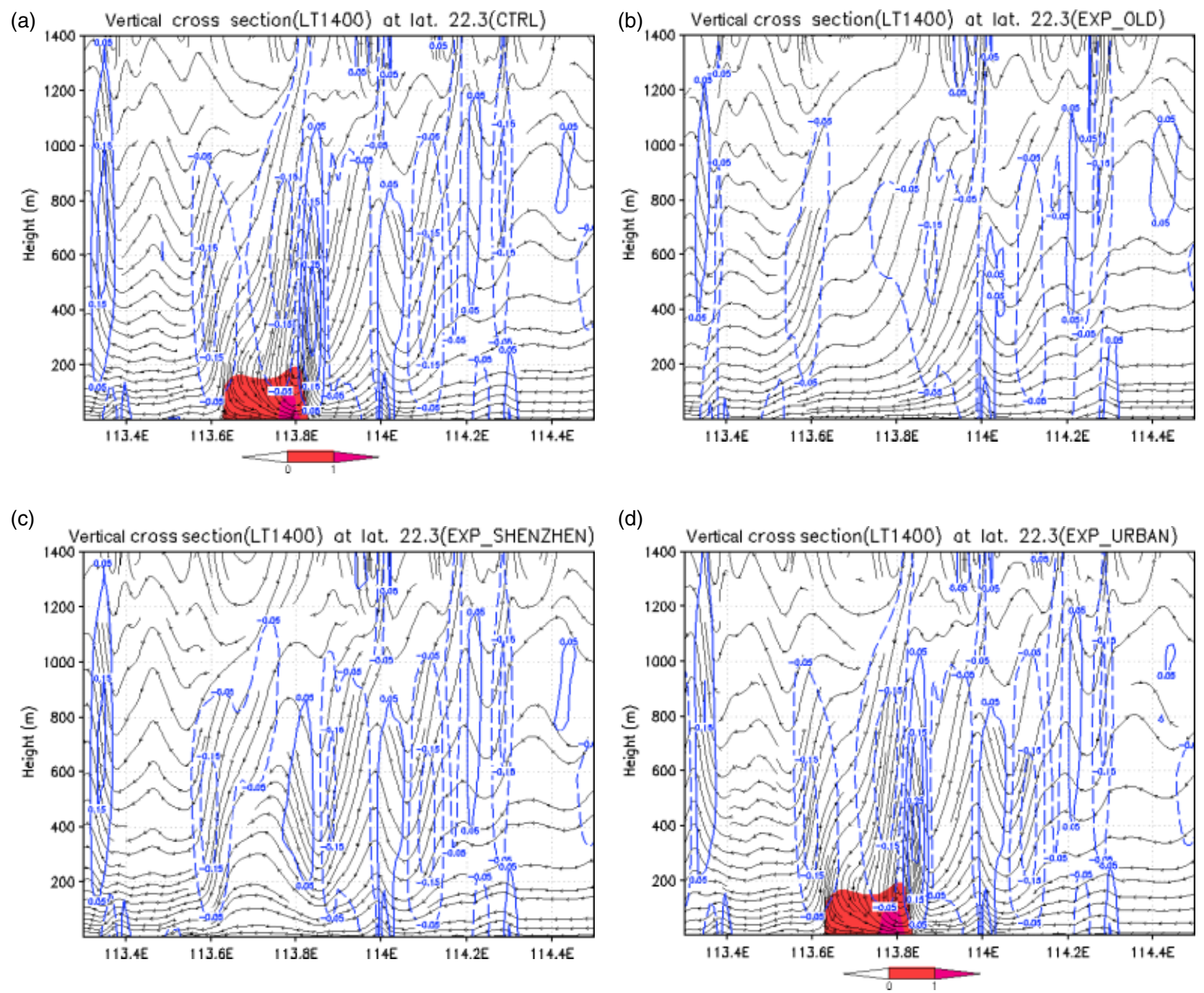

Figure 11. Vertical cross sections at latitude $22.3^{\circ} \mathrm{N}$ in Domain 3 showing the $u-w$ streamlines, vertical velocities (m $\mathrm{s}^{-1}$, contours) and magnitudes of the westerly winds ( $\mathrm{m} \mathrm{s}^{-1}$, shadings) at LT 1400 in experiments (a) CTRL, (b) EXP_OLD, (c) EXP_SHENZHEN,

(d) EXP_URBAN. This figure is available in colour online at www.interscience.wiley.com/ijoc

Three sensitivity experiments with changes in land use have been carried out to investigate the impacts of urbanization in this region. The responses of the LSB circulation to urbanization, which generally correspond to the changes in surface temperature, are most significant around the early afternoon at LT 1400 , and are noticeable in the period from LT 1100 to LT 1600. The results of the experiments suggest that the location of urban development in the PRD region can have important effects on the regional LSB circulation in the afternoon. For instance, the experimental results show that the urbanization of Shenzhen, though relatively small in area compared with the PRD region, may significantly enhance the SBs and the local circulation near the western coast of Hong Kong in the early afternoon. This may increase the low-level convergence in Hong Kong and worsen the air pollution problem there. The effect of urbanization at Shenzhen on this low-level convergence is comparable to that due to the urbanization in the whole PRD region. On the other hand, the experimental results show that an urban development in the western coast of the PRD, though much larger than Shenzhen in area, does not show significant effects on the LSBs in the PRD estuary. Its effects are relatively local and may only affect the afternoon circulation in the western PRD land areas. These results indicate that the effects of urbanization on the regional circulation and LSBs are complicated. Not only are the areas of urbanization important but also the location of the urban areas. This suggests that when planning for future development in some delta or bay regions like the PRD region, numerical studies similar to the present one are worth undertaking.

Finally, it is worth mentioning that the experiments in this study are idealized experiments in which no clouds and precipitation effects are considered. The seasonal solar radiation received at the surface is generally higher than the real situation, which may result in stronger LSBs in the model. As a result, the situations simulated by the model may represent the upper bound of the responses 


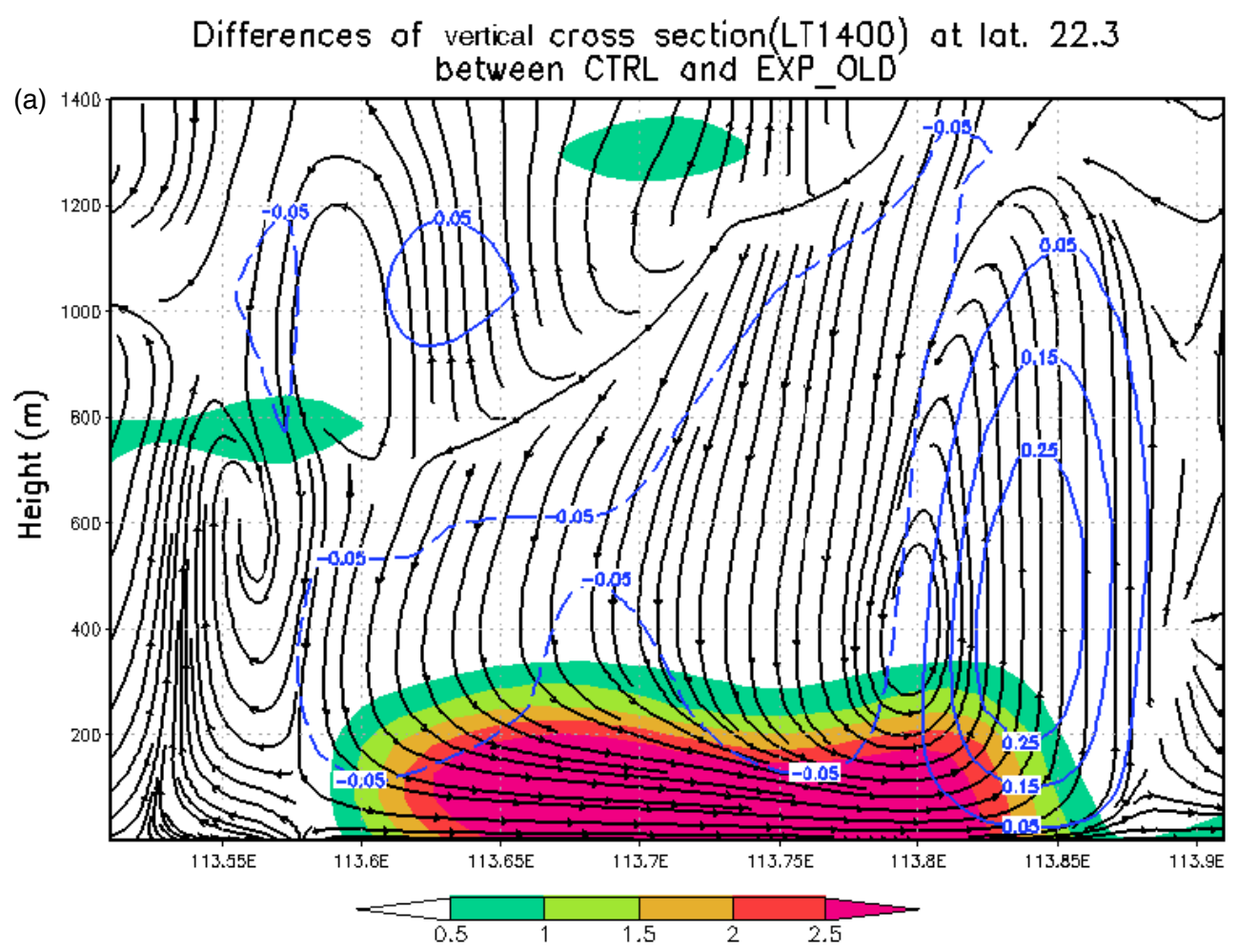

Differences of vertical cross section(LT1400) ot lat. 22.3

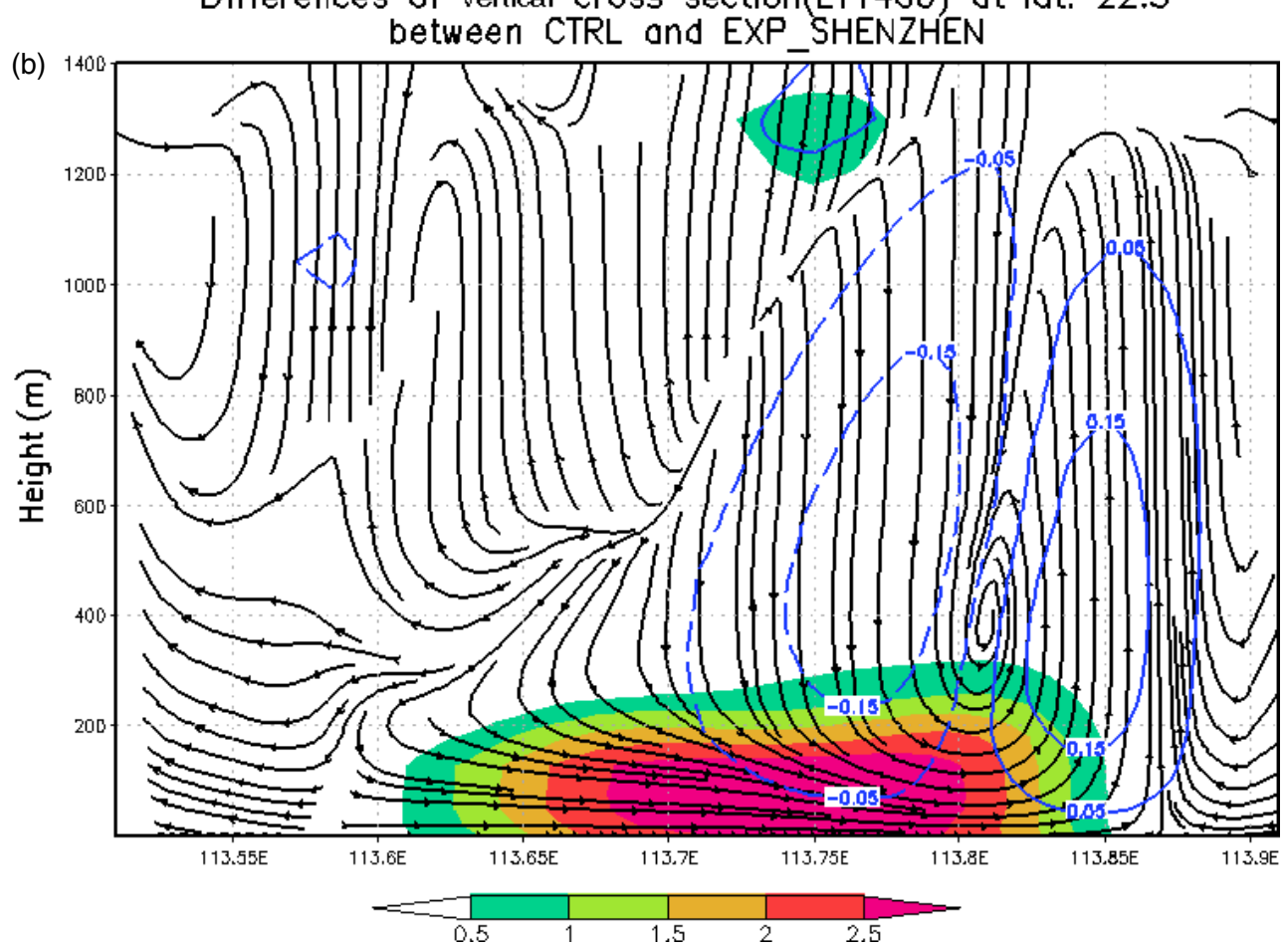

Figure 12. As in Figure 11, but for the differences (CTRL - experiments) in (a) EXP_OLD, (b) EXP_SHENZHEN. This figure is available in colour online at www.interscience.wiley.com/ijoc

due to urbanization, basically corresponding to a fine sunny day in the real situation. Furthermore, this study only considers the changes in the LSB flow field due to the changes in urbanization. Studying the transport of air pollutants associated with these changes in LSBs is worthy of further investigation.

\section{Acknowledgements}

This research was supported by the Atmospheric Research Centre of the HKUST Fok Ying Tung Graduate School, the RGC grants nos. 612807 and 602103, and the RGC/NSFC grant no. N_HKUST631/05. The authors also 


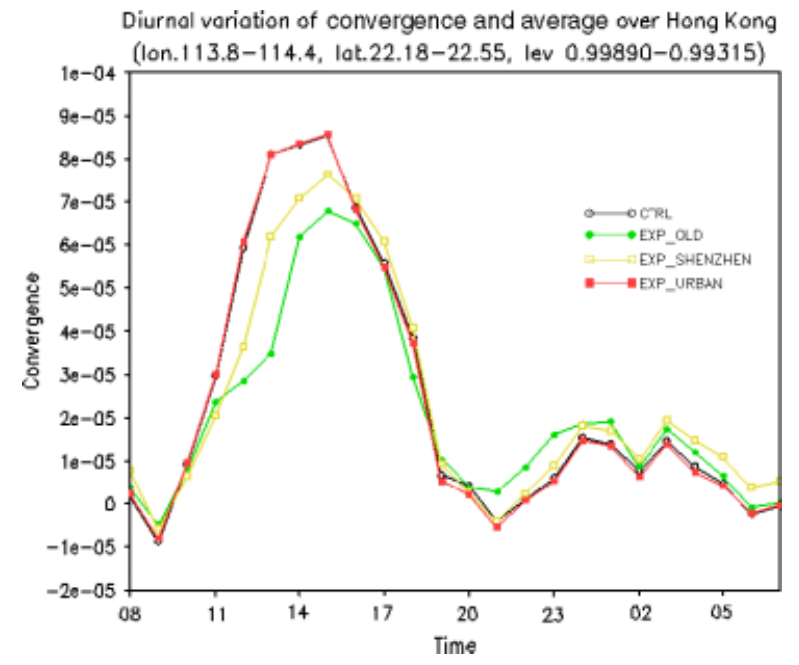

Figure 13. Diurnal variations of area-averaged convergence $\left(\mathrm{s}^{-1}\right)$ over Hong Kong area $\left(113.8-114.4^{\circ} \mathrm{E}, 22.18-22.55^{\circ} \mathrm{N}\right)$ at the lowest troposphere (averaged of the three vertical levels below $50 \mathrm{~m}$ altitude). This figure is available in colour online at www.interscience.wiley.com/ijoc

thank the HKUST ENVF for providing the model data and the Hong Kong Planning Department for the land use data.

\section{References}

Bornstein RD. 1975. The two-dimensional UPBMENT urban boundary layer model. Journal of Applied Meteorology 14: 1459-1477.

Buckley RL, Kurzeja RJ. 1997. An observational and numerical study of nocturnal sea breeze. Part I: structure and circulation. Journal of Applied Meteorology 36: 1577-1598.

Chen F, Dudhia J. 2001. Coupling and advanced land surface hydrology model with the Penn State-NCAR MM5 modeling system. Part I: Model implementation and sensitivity. Monthly Weather Review 129: 569-585.

Ding AJ, Wang T. 2004. Simulation of sea-land breezes and a discussion of their implications on the transport of air pollution during a multi-day ozone episode in the Pearl River Delta of China. Atmospheric Environment 38: 6737-6750.

Dudhia J. 1993. A nonhydrostatic version of the Penn State-NCAR Mesoscale Model: Validation tests and simulation of an Atlantic cyclone and cold front. Monthly Weather Review 121: 1493-1513.

Fung JCH, Lau AKH, Lam JSL, Yuan Z. 2005. Observational and modeling analysis of a severe air pollution episode in western Hong Kong. Journal of Geophysical Research 110(D9): D09105, DOI: 10.1029/2004JD005105.

Guo YR, Chen S. 1994. Terrain and land use for the fifth generation Penn state/NCAR Mesoscale Modeling System (MM5): Program TERRAIN. NCAR Technical Note NCAR/TN-397+IA, 24.
HKPD. 2003. Hong Kong 2030: Planning vision and strategy consultancy study to analyse broad land use pattern of the Pearl River Delta region. Hong Kong 2030 Forum First Executive Summary, Technical paper No. 5, 19 .

Hong SY, Pan HL. 1996. Non-local boundary layer vertical diffusion in a medium range forecast model. Monthly Weather Review 124: $2322-2339$.

Huang JP, Fung JCH, Lau AKH, Qin Y. 2005. Numerical simulation and process analysis of typhoon-related ozone episodes in Hong Kong. Journal of Geophysical Research 110: D05301, DOI:10.1029/2004JD004914.

Kok GL, Lind JA, Fang M. 1997. An airborne study of air quality around the Hong Kong territory. Journal of Geophysical Research 102: 19043-19057.

Lam JSL, Lau AKH, Fung JCH. 2006. Application of refined landuse categories for high resolution mesoscale atmospheric modeling. Boundary-Layer Meteorology 119: 263-288.

Lin WS, Sui CH, Yang LM, Wang XM. 2007. A numerical study of the influence of urban expansion on monthly climate in dry autumn over the Pearl River Delta, China. Theoretical and Applied Climatology 89: 63-72, DOI: $10.1007 / \mathrm{s} 00704-006-0244-6$.

Liu Y, Chen F, Warner T, Basara J. 2006. Verification of a mesoscale data-assimilation and forecasting system for the Oklahoma City area during the joint Urban 2003 field project. Journal of Applied Meteorology and Climatology 45: 912-929.

Lo JCF, Lau AKH, Fung JCH, Chen F. 2006. Investigation of enhanced cross-city transport and trapping of air pollutants by coastal and urban land-sea breeze circulations. Journal of Geophysical Research 111: D14104, DOI: 10.1029/2005JD006837.

Lo JCF, Lau AKH, Chen F, Fung JCH. 2007. Urban modification in a mesoscale model and the effects on the local circulation in the pearl river delta region. Journal of Applied Meteorology and Climatology 46: $457-476$.

Mlawer EJ, Taubman SJ, Brown PD, Iacono MJ, Clough SA. 1997. Radioactive transfer for inhomogeneous atmosphere: RRTM, a validated correlated-k model for the long wave. Journal of Geophysical Research 102: 16663-16682.

Sawai T. 1978. Formation of the urban air mass and the associated local circulation. Journal of the Meteorological Society of Japan 56: $159-174$.

Tong H, Walton A. 2005. Numerical simulation of the urban boundary layer over the complex terrain of Hong Kong. Atmospheric Environment 39: 3549-3563.

Vukovich FM. 1971. Theoretical analysis of the effect of mean wind and stability on a heat island circulation characteristic of an urban complex. Monthly Weather Review 99: 919-926.

Wang XM, Lin WS, Yang LM. 2007. A numerical study of influences of urban land-use change on ozone distribution over the Pearl River Delta region, China. Tellus 59B: 633-638.

Yim SHL, Fung JCH, Lau AKH, Kot JC. 2007. Developing a highresolution wind map for a complex terrain with a coupled MM5/CLAMET system. Journal of Geophysical Research 112: D05106, DOI: 10.1029/2006JD007752.

Zhang LF, Zhang M. 1999. Study of Sea-land Breeze system in the Mouth Area of the Zhuangiiang River. Chinese Journal of the Atmospheric Sciences 23: 581-588. 